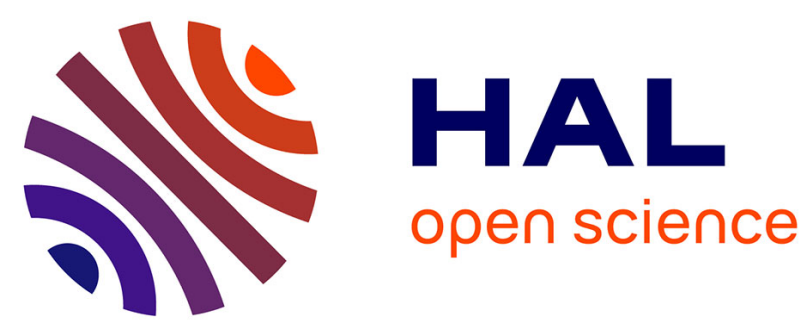

\title{
Porous stage assessment of pressure assisted sintering modeling parameters: a ceramic identification method insensitive to final stage grain growth disturbance
}

Charles Manière, Christelle Harnois, Sylvain Marinel

\section{- To cite this version:}

Charles Manière, Christelle Harnois, Sylvain Marinel. Porous stage assessment of pressure assisted sintering modeling parameters: a ceramic identification method insensitive to final stage grain growth disturbance. Acta Materialia, 2021, 211, pp.116899. 10.1016/j.actamat.2021.116899 . hal-03404081

\section{HAL Id: hal-03404081 \\ https://cnrs.hal.science/hal-03404081}

Submitted on 27 Oct 2021

HAL is a multi-disciplinary open access archive for the deposit and dissemination of scientific research documents, whether they are published or not. The documents may come from teaching and research institutions in France or abroad, or from public or private research centers.
L'archive ouverte pluridisciplinaire HAL, est destinée au dépôt et à la diffusion de documents scientifiques de niveau recherche, publiés ou non, émanant des établissements d'enseignement et de recherche français ou étrangers, des laboratoires publics ou privés. 


\title{
Porous stage assessment of pressure assisted sintering modeling parameters: a ceramic identification method insensitive to final stage grain growth disturbance
}

\author{
Charles Manière ${ }^{1} *$, Christelle Harnois ${ }^{1}$, Sylvain Marinel ${ }^{1}$
}

1. Normandie Univ, ENSICAEN, UNICAEN, CNRS, CRISMAT, 14000, Caen, France

\section{Keywords}

Sintering ; Ceramic; Modeling; High temperature testing; Grain growth

\begin{abstract}
Pressure assisted sintering models such as Skorohod-Olevsky's, Abouaf's or Riedel's require the identification of at least four parameters depending on porosity or temperature. The identification of these parameters is difficult at high temperature and for high pressures because of the non-linear mechanical behavior which makes them closely interconnected. To solve this problem, the fully dense behavior is identified first allowing determining the porous behavior afterward. This typical approach is well employed for metal or viscous materials. However, for ceramics the final stage grain growth makes the fully dense mechanical tests irrelevant; because the equivalent dense phase behavior of sintered specimens has bigger grains (then longer diffusion distances) than in initial/intermediate stages of sintering. Consequently, most of the parameters of these ceramics models compensate the dense parameters overestimation by an underestimation in the porous parameters values. In this paper we propose a unique formulation based on sinter-forging and die compaction which directly identify all the parameters from the porous stage. This comprehensive determination is possible by a non-reductive hypothesis on the shear modulus function shape and the experimental determination of radial/vertical displacement on sinter-forging tests. Such an approach allows an instantaneous determination of the parameters insensitive from the actual grain size of the porous ceramic.
\end{abstract}

\footnotetext{
* Corresponding author: CM: Laboratoire de cristallographie et sciences des matériaux (CRISMAT), 6 Bvd du maréchal Juin 14050 CAEN CEDEX 4, France

Ph.: +33.2.31.45.13.69; E-mail address: charles.maniere@ensicaen.fr
} 


\section{Nomenclature}

$\theta$ Porosity

$\dot{\theta}$ Porosity elimination rate $\left(\mathrm{s}^{-1}\right)$

$\rho$ Relative density

$\underline{\sigma}$ Stress tensor $\left(\mathrm{N} . \mathrm{m}^{-2}\right)$

$\underline{s}$ Deviatoric stress tensor (N.m ${ }^{-2}$ )

$\sigma_{e q}$ Equivalent stress (N.m $\left.{ }^{-2}\right)$

$\underline{\dot{\varepsilon}}$ Strain rate tensor $\left(\mathrm{s}^{-1}\right)$

$\dot{\varepsilon}_{e q}$ Equivalent strain rate $\left(\mathrm{s}^{-1}\right)$

$n$ Creep law stress exponent

$A$ Creep law deformability term $\left(\mathrm{s}^{-1} \mathrm{~Pa}^{-\mathrm{n}}\right)$

$A_{0}$ Deformability pre-exponential factor $\left(\mathrm{Ks}^{-1} \mathrm{~Pa}^{-\mathrm{n}}\right)$

$Q$ Deformability activation energy (J.mol $\left.{ }^{-1}\right)$

$R$ Gas constant $8.314\left(\mathrm{~J} \cdot \mathrm{mol}^{-1} \cdot \mathrm{K}^{-1}\right)$

$T$ Temperature (K)

$\varphi$ Shear modulus

$\psi$ Bulk modulus

$P l$ Sintering stress $(\mathrm{Pa})$

in Identity tensor

$\alpha$ Surface energy (J.m $\left.{ }^{-2}\right)$

$r$ Particles radius $(\mathrm{m})$

$\dot{e}$ Trace of the strain rate tensor $\left(\mathrm{s}^{-1}\right)$

$\dot{\gamma}$ Shear strain rate invariant $\left(\mathrm{s}^{-1}\right)$

$P$ Hydrostatic stress $\left(\mathrm{N} . \mathrm{m}^{-2}\right)$

$\tau$ Shear stress invariant $\left(\mathrm{N} . \mathrm{m}^{-2}\right)$

$I_{1}$ Trace of the stress tensor $\left(\mathrm{N} . \mathrm{m}^{-2}\right)$

$\dot{\varepsilon}_{r}$ Radial strain rate tensor component $\left(\mathrm{s}^{-1}\right)$

$\dot{\varepsilon}_{z}$ Axial strain rate tensor component $\left(\mathrm{s}^{-1}\right)$

$\sigma_{r}$ Radial stress tensor component (N.m ${ }^{-2}$ )

$\sigma_{z}$ Axial stress tensor component (N.m ${ }^{-2}$ )

$s_{r}$ Radial deviatoric stress tensor component (N.m $\left.{ }^{-2}\right)$

$s_{Z}$ Axial deviatoric stress tensor component (N.m ${ }^{-2}$ )

$\theta_{c}$ Critical porosity

$\mu$ Bulk modulus exponent

$a, b, c$ Fitting constants

$t$ Time (s) 


\section{$H$ A constant}

$D$ Diffusion coefficient $\left(\mathrm{m}^{2} . \mathrm{S}^{-1}\right)$

$k$ Boltzmann Constant $\left(1.380649 \times 10^{-23}{\left.\mathrm{~J} . \mathrm{K}^{-1}\right)}^{-1}\right.$

$\phi$ Stress intensification factor

HIP Hot isostatic pressing

SPS Spark Plasma Sintering

HP Hot pressing

SF Sinter-forging

\section{Graphical Abstract}

PRESSURE ASSISTED SINTERING MODEL IDENTTFICATION FOR CERAMUCS

$$
\underline{\dot{\varepsilon}}=A(T, G) \sigma_{e q}^{n-1}\left(\frac{s}{\varphi(\theta)}+\frac{I_{1}}{9 \psi(\theta)} \stackrel{\mathbb{1}}{)} \nabla_{A(T, G), n} \quad \dot{\varepsilon}_{e q}=A^{\prime}(T, G) \sigma_{e q}^{n \prime}\right.
$$
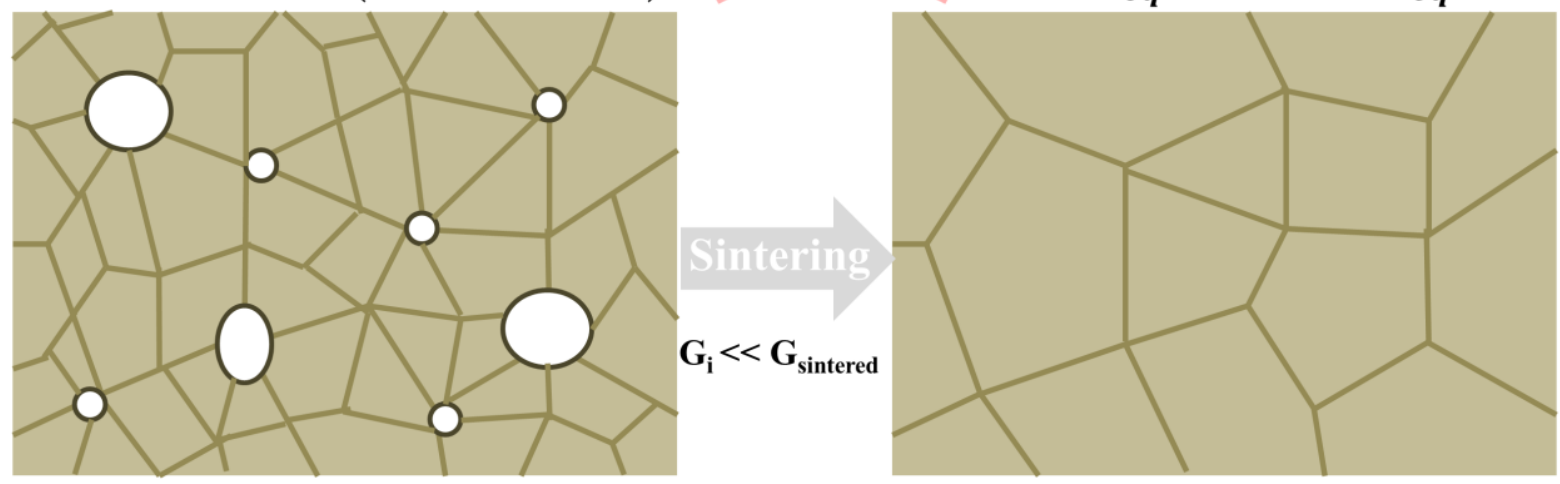

$$
\frac{(n+1)}{2} \ln \left(1-\frac{\theta}{\theta_{c}}\right)
$$

\section{Sinter-forging}
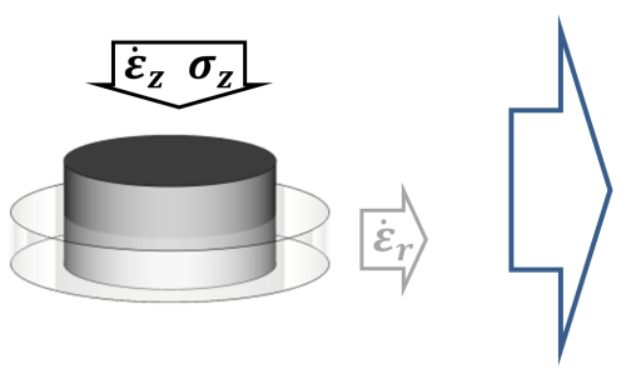

$-1.3-1.1$

$-0.5$

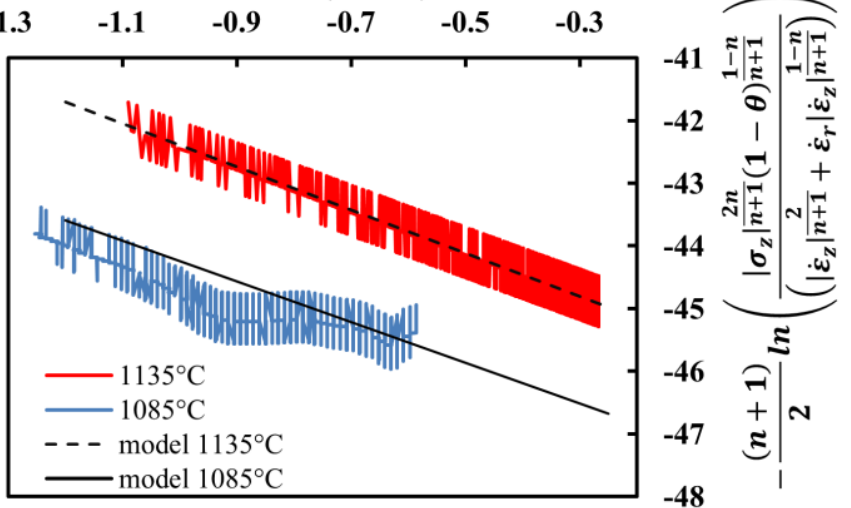




\section{Introduction}

The modeling of the sintering of ceramics is a way to predict the sintering trajectory[1], optimize the heating cycle[2], model the specimen distortions during free-sintering[3] and determine the specimen porosity distribution for pressure-assisted sintering[4]. Consequently, the modeling of sintering is of primary interest in the field of high-performance ceramics, including the design of complex shapes ceramics [5].

Despite the previous cited advantages, one of the main issues of the sintering modeling is the identification of all the sintering mechanical parameters characterizing the high temperature shear and bulk porous medium behavior. Numerous theoretical laws[6-9] have been employed to circumvent this issue allowing fast identification from limited mechanical tests[10,11]. However, most of these theoretical laws suffer from a high degree of idealization and corrective approaches $[12,13]$ are employed for ensuring an accurate model prediction of the experiments. Therefore, full experimental model identification is more desirable for obtaining a stable model in a wide experimental domain. Traditionally, the identification method consists of creep tests on fully sintered specimens and numerous mechanical tests based on porous specimens to capture the shear and bulk mechanical behavior[14]. Hot isostatic pressing (HIP) tests coupled with sinter-forging (SF) are typically employed by Nicolle [15] and Besson [16]. In these studies, interrupted HIP cycles were employed by a fast release of the pressure and temperature[15]. This method allows an independent determination of the hydrostatic behavior. However, the experimental methodology is very time consuming and only a few HIP equipment allow quenching the specimens. As proposed by Abouaf [14], the HIP tests may be replaced by confined hot pressing tests (HP). This method has been applied to "astroloy" alloy [17] and lead[18,19]. In previous studies, the latter method has been adapted to the spark plasma sintering (SPS) in die pressing and sinterforging configurations for Ti6AlV [20], nickel [21] and TiAl [22]. 
The previous traditional experimental approach allows obtaining very accurate sintering models for material relatively insensitive to microstructural evolution such as the sintering of large particles metals, viscous, vitrification and liquid phase sintering, etc. Sintering models should reflect numerous underlying phenomena competing to each other and requiring an extensive experimental identification of parameters which are temperature and porosity dependent. These phenomena are the densification $v s$ grain growth[23,24], the pore coarsening by surface diffusion[25], the changes of sintering mechanisms[2,26], etc. For ceramics, the equivalent creep behavior is an important underlying dense phase phenomena governing the densification kinetics. The latter is very sensitive to the microstructure at the final stage where the grain growth extends the diffusion distances (by the grain boundaries or lattice) and then decreases the densification kinetics[27,28]. This aspect is limiting the traditional experimental methods consisting of the identification of the fully sintered creep behavior $(A(T)$ and $n$ on the right figure 1a) and the injection of these parameters for the identification of porous unknown parameters from porous tests $(\varphi(\theta)$ and $\psi(\theta)$ on the left figure 1a). The explanation of these parameters will be detailed in the theory and calculation section. For ceramics, the grain growth phenomenon disturbs the creep behavior[23]. The sintered specimen having larger grain implies slower creep kinetics $\left(A^{\prime}(T)\right.$ and $n^{\prime}$ on the right figure $1 \mathrm{~b}$ ) than the equivalent dense phase at porous stages $(A(T)$ and $n$ on the right figure $1 \mathrm{~b})$. Therefore, a method needs to be found in order to identify both the creep and the shear/bulk moduli $(\varphi(\theta)$ and $\psi(\theta))$ from porous stage.

The aim of this study is to find a solution to solve the grain growth issue of sintering parameters identification for ceramics (or other microstructure dependent materials). The main challenge of this study will be to identify a combination of porous high temperature mechanical tests allowing an independent identification of the temperature/pressure/porous mechanical shear and bulk sintering behavior. Later, we will see that such objective can be achieved combining die pressing and sinter-forging tests with vertical/radial displacement information. This result allows identifying the sintering behavior independently and for a very 
restricted temperature/porosity domain of a ceramic without the problem of grain growth disturbance of the creep behavior. Such an approach can be generalized to all materials experiencing similar microstructural evolution disturbance such as for metal and alloys with phase transition or submicron grain powders.

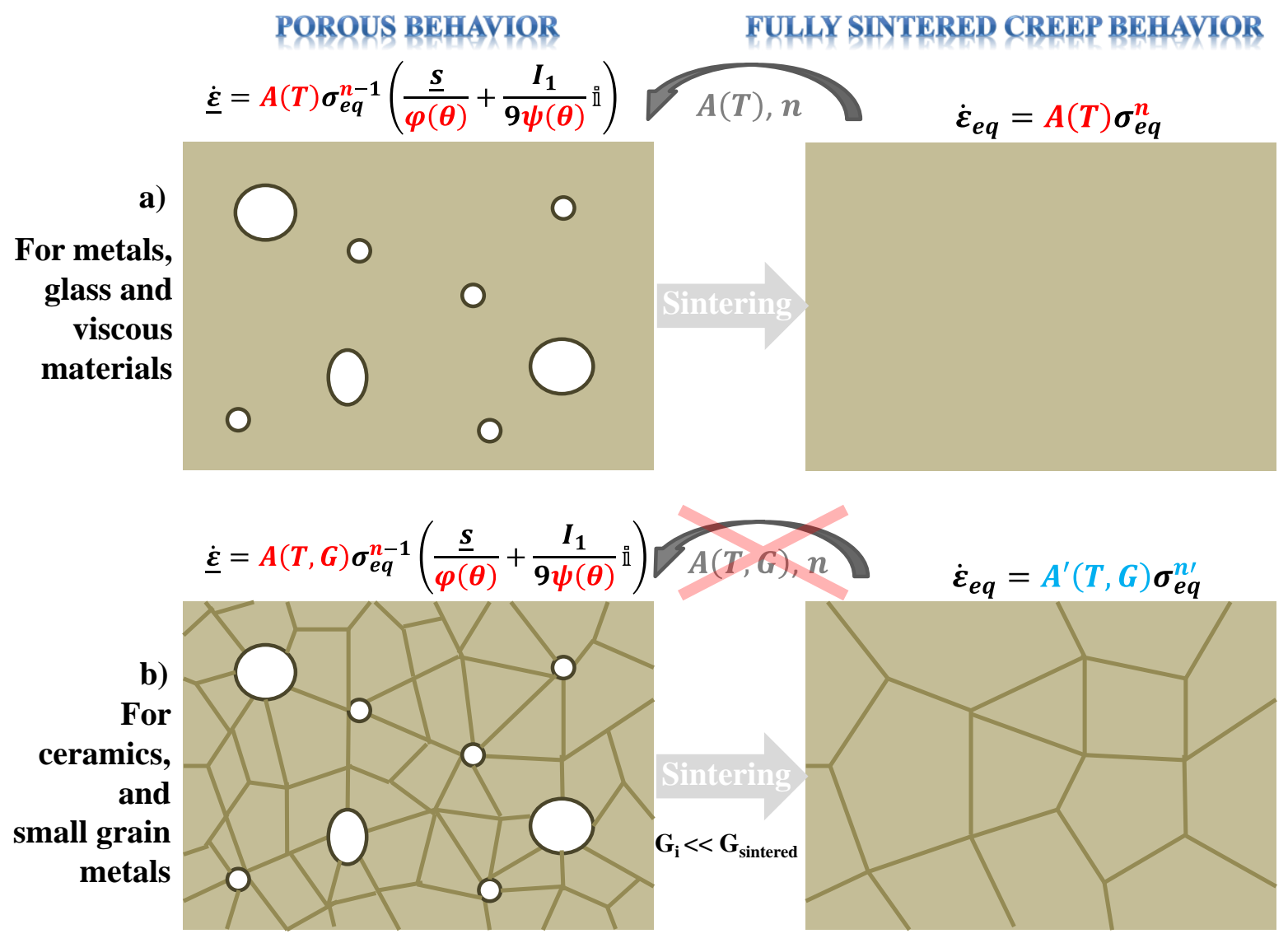

Figure 1 Pressure assisted sintering parameters (in red) identification method, a) for materials without dense phase (sand color) microstructure evolution, $b$ ) case of ceramic having final stage grain growth and a different dense phase creep behavior than the equivalent dense phase at porous stage.

\section{Theory and calculations}

In this section, the general equations of the continuum theory of sintering [29] will be detailed first. The analytical equations for the particular cases of die pressing and sinter-forging will be subsequently expressed by the general theory. Finally, the formulation of the system of analytical equations for the sintering model identification from porous stage will be presented. 


\subsection{Model description}

The continuum theory of sintering [29] considers a creep underlying dense phase behavior where the equivalent stress and strain rate equations obey Norton creep law.

$\dot{\varepsilon}_{e q}=A(T, G) \sigma_{e q}{ }^{n}$

The term A includes numerous physical constants from the creep theory, the grain size and the diffusion coefficient, it is defined by Arrhenius form:

$A(T, G)=A_{0}\left(\frac{G_{0}}{G}\right)^{m} \frac{\exp \left(\frac{-Q}{R T}\right)}{T}$

This equation shows that the grain growth highly influences the creep behavior. In the case of grain boundary diffusion $(m=3)$, increasing the grain size twice divides the creep strain rate by a factor 8 . The creep behavior reported in the literature [30] on sintered ceramics can hence not be considered at porous stage, since grain sizes are different at least by a factor 5 .

The equivalent stress and strain rate tensors are defined by:

$\sigma_{e q}=\frac{\sqrt{\frac{\tau^{2}}{\varphi}+\frac{\left(P-P_{l}\right)^{2}}{\psi}}}{\sqrt{1-\theta}}$

$\dot{\varepsilon}_{e q}=\frac{1}{\sqrt{1-\theta}} \sqrt{\varphi \dot{\gamma}^{2}+\psi \dot{e}^{2}}$

Where $\varphi$ and $\psi$ are unknown functions of the porosity needing to be determined experimentally. The terms $\tau, P, \dot{\gamma}$ and $\dot{e}$ are the stress and strain rate invariants defined below.

$\tau=\frac{\sqrt{\left(\sigma_{x}-\sigma_{y}\right)^{2}+\left(\sigma_{y}-\sigma_{z}\right)^{2}+\left(\sigma_{z}-\sigma_{x}\right)^{2}+6\left(\sigma_{x y}^{2}+\sigma_{y z}^{2}+\sigma_{x z}^{2}\right)}}{\sqrt{3}}$

$P=\frac{\sigma_{x}+\sigma_{y}+\sigma_{z}}{3}=\frac{I_{1}}{3}$

$\dot{\gamma}=\sqrt{2\left(\dot{\varepsilon}_{x y}^{2}+\dot{\varepsilon}_{x z}^{2}+\dot{\varepsilon}_{y z}^{2}\right)+\frac{2}{3}\left(\dot{\varepsilon}_{x}^{2}+\dot{\varepsilon}_{y}^{2}+\dot{\varepsilon}_{z}^{2}\right)-\frac{2}{3}\left(\dot{\varepsilon}_{x} \dot{\varepsilon}_{y}+\dot{\varepsilon}_{x} \dot{\varepsilon}_{z}+\dot{\varepsilon}_{y} \dot{\varepsilon}_{z}\right)}$

$\dot{e}=\dot{\varepsilon}_{x}+\dot{\varepsilon}_{y}+\dot{\varepsilon}_{z}$

The term $P_{l}$ is the Laplace stress originated from particle capillarity forces. The latter can be defined by the particle radius and the porosity from Skorohod theory [6,29].

$P l=\frac{3 \alpha}{r}(1-\theta)^{2}$ 
Finally, the sintering behavior of a continuum can be defined by:

$\underline{\sigma}=\frac{\sigma_{e q}}{\dot{\varepsilon}_{e q}}\left(\varphi \underline{\dot{\varepsilon}}+\left(\psi-\frac{1}{3} \varphi\right) \dot{e} \mathbb{1}\right)+P_{l} \underline{\mathbb{1}}$

Similarly, the strain rate formulation of the continuum sintering model can be obtained using below equations [29];

$\left\{\begin{array}{c}P=\frac{\sigma_{e q}}{\dot{\varepsilon}_{e q}} \psi \dot{e}+P_{l} \\ \tau=\frac{\sigma_{e q}}{\dot{\varepsilon}_{e q}} \varphi \dot{\gamma}\end{array}\right.$

and the stress tensor deviatoric expression,

$\underline{\sigma}=\underline{s}+\frac{1}{3} I_{1} \underline{\mathbb{1}}$

The strain rate formulation is then:

$\underline{\dot{\varepsilon}}=\frac{\dot{\varepsilon}_{e q}}{\sigma_{e q}}\left(\frac{\underline{s}}{\varphi}+\frac{\left(P-P_{l}\right)}{3 \psi} \underline{\mathbb{1}}\right)$

Finally, the mass conservation is used to link the volume change rate and the rate of porosity elimination.

$\frac{\dot{\theta}}{(1-\theta)}=\dot{e}$

\subsection{Analytical equations for die pressing SPS}

SPS can be assimilated to a high temperature die pressing test (along the z-axis). Therefore, if the lateral powder/die friction is neglected due to the graphite foil double interface [31], the external strain rate tensor is reduced to:

$\underline{\dot{\varepsilon}} \equiv\left(\begin{array}{ccc}0 & 0 & 0 \\ 0 & 0 & 0 \\ 0 & 0 & \dot{\varepsilon}_{z}\end{array}\right)$

With (1), (10) (8) and (15), and neglecting the capillarity forces compared to the applied stress $\left(P_{l} \ll \sigma_{z}\right)$ the stress $\mathrm{z}$ component is:

$\sigma_{z}=\frac{\dot{\varepsilon}_{e q^{\frac{1}{n}-1}}}{A(T, G)^{\frac{1}{n}}}\left(\varphi \dot{\varepsilon}_{z}+\left(\psi-\frac{1}{3} \varphi\right) \dot{\varepsilon}_{z}\right)$

Based on equation (15), the following simplification can be made. 
$\dot{e}=\dot{\varepsilon}_{z}, \dot{\gamma}=\left|\dot{\varepsilon}_{z}\right| \sqrt{\frac{2}{3}}, \dot{\varepsilon}_{e q}=\left|\dot{\varepsilon}_{z}\right| \sqrt{\frac{\psi+\frac{2}{3} \varphi}{1-\theta}}$

The analytical SPS equation is then:

$\left|\dot{\varepsilon}_{z}\right|=A(T, G)\left(\psi+\frac{2}{3} \varphi\right)^{\frac{-n-1}{2}}(1-\theta)^{\frac{1-n}{2}}\left|\sigma_{z}\right|^{n}$

This equation can be compared to the solid state sintering models (see appendix). If the capillarity forces $P_{l}$ are not negligible and the applied stress is strong enough to ensure no radial shrinkage $\left(\dot{\varepsilon}_{r}=0\right)$ the equation (18) becomes:

$\dot{\varepsilon}_{z}=A(T, G)\left(\psi+\frac{2}{3} \varphi\right)^{\frac{-n-1}{2}}(1-\theta)^{\frac{1-n}{2}}\left(\sigma_{z}-P_{l}\right)^{n}$

\subsection{SPS based $n$ and $Q$ determination}

Equation (18) ca be used to identify $n$ by an isothermal SPS test at two pressures and Q by an isobar SPS test at two temperatures like for Dorn's method[32-34]. It is possible to determine these creep parameters directly from an SPS curve considering theoretical moduli[4,35]. However, from the literature, the theoretical value of the moduli is often overestimated $[12,16]$ (see the literature modulus comparison at the end of the article). This can imply a compensation of the creep parameters to correct the moduli overestimation[10]. The advantage of the method described below, which is based on two curves, is to identify the creep parameters $n$ and $Q$ at fixed porosity while removing the possible disturbances from the unknown moduli functions.

\subsection{1. . determination of $n$}

Using mass conservation (14) and equation (18) we obtain:

$\left|\frac{\dot{\theta}}{(1-\theta)}\right|=A(T, G)\left(\psi+\frac{2}{3} \varphi\right)^{\frac{-n-1}{2}}(1-\theta)^{\frac{1-n}{2}}\left|\sigma_{z}\right|^{n}$

For two die compaction tests at the same T, $\theta$ and at different applied stress $\left(\sigma_{z}\right)$, we obtain:

$\left|\frac{\dot{\theta}_{1}}{\dot{\theta}_{2}}\right|=\left|\frac{\sigma_{1}}{\sigma_{2}}\right|^{n}$

And then :

$n=\frac{\ln \left(\frac{\dot{\theta}_{1}}{\dot{\theta}_{2}}\right)}{\ln \left(\frac{\sigma_{1}}{\sigma_{2}}\right)}$ 
The identification methodology is reported in figure $2 \mathrm{a}$, the value of $n$ can then be determined by the measurement the $\dot{\theta}_{i}$ for different $\sigma_{i}$ at same $\theta$ and T.

If the capillarity forces $P_{l}$ are not negligible equation (22) becomes:

$n=\frac{\ln \left(\frac{\dot{\theta}_{1}}{\dot{\theta}_{2}}\right)}{\ln \left(\frac{\sigma_{1}-P_{l}}{\sigma_{2}-P_{l}}\right)}$

\subsubsection{Determination of $Q$}

Die compaction tests can also be employed to determine the creep law activation energy $Q$ via a collection of tests at different temperatures. Taking the temperature dependence of $A$ and equation (20), we have:

$\left|\frac{\dot{\theta}}{(1-\theta)}\right|=A_{0}(G) \frac{\exp \left(\frac{-Q}{R T}\right)}{T}\left(\psi+\frac{2}{3} \varphi\right)^{\frac{-n-1}{2}}(1-\theta)^{\frac{1-n}{2}}\left|\sigma_{z}\right|^{n}$

Then, for two die compaction tests at same $\theta$, applied stress $\left(\sigma_{z}\right)$ and for different temperatures, we have:

$\left|\dot{\theta}_{1}\right| \frac{T_{1}}{\dot{\theta}_{2}} \mid \frac{\exp \left(\frac{-Q}{R T_{1}}\right)}{\exp \left(\frac{-Q}{R T_{2}}\right)}=\exp \left(\frac{Q}{R T_{2}}-\frac{Q}{R T_{1}}\right)=\exp \left(\frac{Q}{R}\left(\frac{1}{T_{2}}-\frac{1}{T_{1}}\right)\right)$

the activation energy $Q$ is then determined by:

$Q=\frac{R \ln \left(\frac{\dot{\theta}_{1} T_{1}}{\dot{\theta}_{2} T_{2}}\right)}{\left(\frac{1}{T_{2}}-\frac{1}{T_{1}}\right)}$

As reported in figure $2 \mathrm{~b}$, the value of $Q$ can be determined by the measurement the $\dot{\theta}_{i}$ for different $T_{i}$ at same $\theta$ and applied stress $\sigma_{z}$ (see following figure). 
a) $n$ EXPONENT IDEENTIFICATION
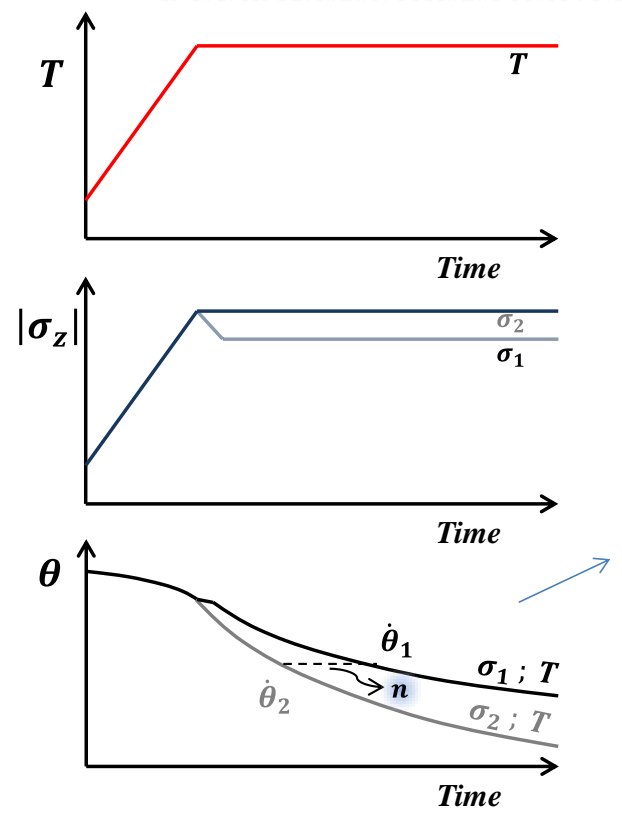

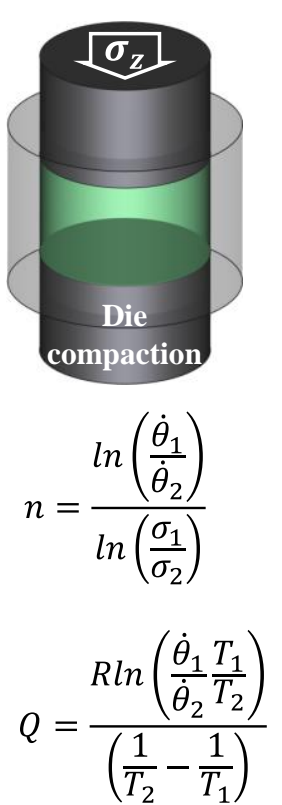

b) ACTIVATTION ENERGY IDENTIFICATION

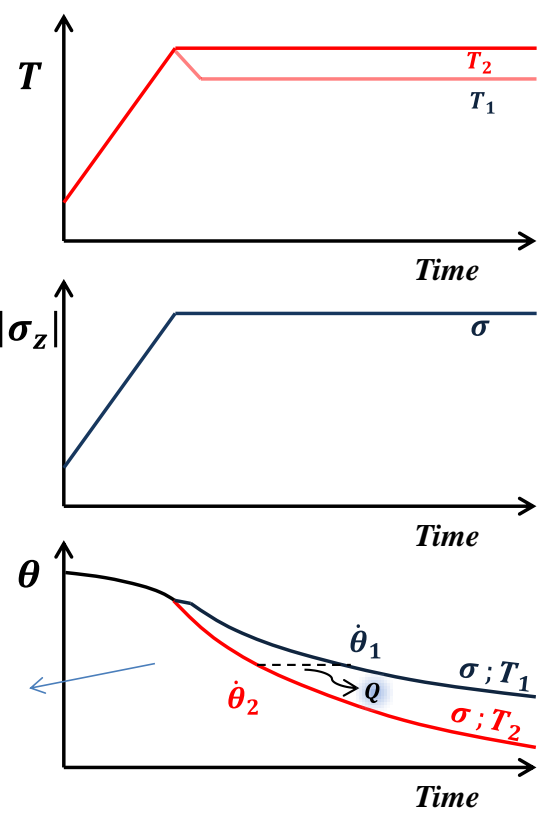

Figure 2 Die pressing based identification method for the creep law (a) exponent $n$ and $(b)$ activation energy $Q$.

\subsection{Analytical equations for sinter-forging}

Sinter-forging configuration consists of a free compression of a porous sample at high temperature. In SPS, this configuration is applied by placing a porous pre-consolidated sample in a larger die. Assuming no thermal gradients, no friction, neglecting the capillarity forces $\left(P_{l} \ll \sigma_{z}\right)$ and a homogeneous stress field, the following simplifications are applied to sinter-forging.

$\underline{\sigma} \equiv\left(\begin{array}{ccc}0 & 0 & 0 \\ 0 & 0 & 0 \\ 0 & 0 & \sigma_{z}\end{array}\right) ; \underline{\dot{\varepsilon}} \equiv\left(\begin{array}{ccc}\dot{\varepsilon}_{r} & 0 & 0 \\ 0 & \dot{\varepsilon}_{r} & 0 \\ 0 & 0 & \dot{\varepsilon}_{z}\end{array}\right) ; \tau=\sqrt{\frac{2}{3}}\left|\sigma_{z}\right| ; P=-\frac{\left|\sigma_{z}\right|}{3}$

The equivalent stress (3) becomes,

$\sigma_{e q}=\left|\sigma_{z}\right| \frac{\sqrt{\frac{2}{3 \varphi}+\frac{1}{9 \psi}}}{\sqrt{1-\theta}}$

and equation (12) becomes,

$S_{z}=\sigma_{z}-\frac{1}{3} I_{1}=-\frac{2}{3}\left|\sigma_{z}\right|$

Injecting the previous simplifications in equation (13), we obtain, 
$\dot{\varepsilon}_{z}=A(T, G)\left(\left|\sigma_{z}\right| \frac{\sqrt{\frac{2}{3 \varphi}+\frac{1}{9 \psi}}}{\sqrt{1-\theta}}\right)^{n-1} \quad\left|\sigma_{z}\right|\left(\frac{-2}{3 \varphi}+\frac{-1}{9 \psi}\right)$

The final expression describing the sinter-forging case is then,

$$
\left|\dot{\varepsilon}_{z}\right|=A(T, G)(1-\theta)^{\frac{1-n}{2}}\left(\frac{2}{3 \varphi}+\frac{1}{9 \psi}\right)^{\frac{n+1}{2}}\left|\sigma_{z}\right|^{n}
$$

As highlighted by Abouaf et al [14,17], at the initial stage sintering the particle point contacts cause quasi-instantaneous creep or rearranging implying the moduli tends to close zero at this stage.

\subsection{Analytical equations for sinter-forging using radial displacement data}

The radial component of the strain rate tensor is expressed as below from equation (13) assuming similar hypothesis of equation (27).

$\dot{\varepsilon}_{r}=A(T, G)\left(\left|\sigma_{z}\right| \frac{\sqrt{\frac{2}{3 \varphi}+\frac{1}{9 \psi}}}{\sqrt{1-\theta}}\right)^{n-1}\left(\frac{s_{r}}{\varphi}+\frac{\sigma_{z}}{9 \psi}\right)$

The radial term deviatoric stress component is defined below,

$S_{r}=\sigma_{r}-\frac{\sigma_{z}}{3}=\frac{\left|\sigma_{z}\right|}{3}$, with $\sigma_{r}=0$

Equation (32) becomes,

$\dot{\varepsilon}_{r}=A(T, G)\left|\sigma_{z}\right|^{n}\left(\frac{\frac{2}{3 \varphi}+\frac{1}{9 \psi}}{1-\theta}\right)^{\frac{n-1}{2}}\left(\frac{1}{3 \varphi}-\frac{1}{9 \psi}\right)$

Using the axial sinter-forging equation (31), we can isolate below moduli expression.

$$
\left(\frac{2}{3 \varphi}+\frac{1}{9 \psi}\right)=A(T, G)^{\frac{-2}{n+1}}\left|\sigma_{z}\right|^{\frac{-2 n}{n+1}}\left|\dot{\varepsilon}_{z}\right|^{\frac{2}{n+1}}(1-\theta)^{\frac{n-1}{n+1}}
$$

As the axial (31) and radial (34) terms originate from a same sinter-forging test, the porosity and then the shear and bulk moduli are the same at each time of the experiment. Consequently, it is possible to inject equation (35) into equation (34).

With below calculations: 


$$
\left\{\begin{array}{c}
A A^{\frac{-2}{n+1}} \frac{n-1}{2}=A \frac{2}{\overline{n+1}} \\
\left|\sigma_{Z}\right|^{n}\left|\sigma_{Z} \frac{-2 n}{\frac{2 n}{n+1}} \frac{n-1}{2}=\right| \sigma_{Z} \frac{2 n}{n+1} \\
\left.\left|\dot{\varepsilon}_{Z} \frac{2}{n+1} \frac{n-1}{2}=\right| \dot{\varepsilon}_{Z}\right|^{\frac{n-1}{n+1}} \\
(1-\theta)^{\frac{n-1}{n+1} \frac{n-1}{2}}(1-\theta)^{\frac{1-n}{2}}=(1-\theta)^{\frac{1-n}{n+1}}
\end{array}\right.
$$

the final analytical expression of the radial strain rate is:

$$
\dot{\varepsilon}_{r}=A(T, G)^{\frac{2}{n+1}}\left|\sigma_{z}\right|^{\frac{2 n}{n+1}}\left|\dot{\varepsilon}_{z}\right|^{\frac{n-1}{n+1}}(1-\theta)^{\frac{1-n}{n+1}}\left(\frac{1}{3 \varphi}-\frac{1}{9 \psi}\right)
$$

If the capillarity forces $P_{l}$ are not negligible, equations (31) and (37) become:

$$
\begin{aligned}
& \dot{\varepsilon}_{Z}=A(T, G)\left(\frac{\frac{2\left|\sigma_{Z}\right|^{2}}{3 \varphi}+\frac{\left(-\frac{\left|\sigma_{Z}\right|}{3}-P_{l}\right)^{2}}{\psi}}{1-\theta}\right)^{\frac{n-1}{2}}\left(-\frac{2\left|\sigma_{Z}\right|}{3 \varphi}+\frac{\left(-\frac{\left|\sigma_{Z}\right|}{3}-P_{l}\right)}{3 \psi}\right) \\
& \dot{\varepsilon}_{r}=A(T, G)\left(\frac{\frac{2\left|\sigma_{Z}\right|^{2}}{3 \varphi}+\frac{\left(-\frac{\left|\sigma_{Z}\right|}{3}-P_{l}\right)^{2}}{\psi}}{1-\theta}\right)^{\frac{n-1}{2}}\left(\frac{\left|\sigma_{Z}\right|}{3 \varphi}+\frac{\left(-\frac{\left|\sigma_{Z}\right|}{3}-P_{l}\right)}{3 \psi}\right)
\end{aligned}
$$

A similar $n, Q$ identification method of sections 2.3.1 and 2.3.2 can also be applied to sinterforging. However, the main difficulty will be the estimation of the actual porosity requiring a radial displacement measurement probe. In comparison, the method based on die compaction can be directly applied in a simple SPS configuration and will be preferred in this study. Nevertheless, the identification method of $n$ and $Q$ is described below as these equations can be precious to check the overall methodology and highlight experimental discrepancies such as a dissimilar mechanical behavior due to temperature measurement error.

\subsubsection{Determination of $n$ based on sinter-forging}

For two sinter-forging compaction tests at the same T, $\theta$ and at different $\sigma_{z}$, with $P_{l} \ll \sigma_{z}$ and using equation (31) at two isothermal pressures, we obtain the ratio:

$$
\left|\frac{\dot{\varepsilon}_{z 1}}{\dot{\varepsilon}_{z 2}}\right|=\left|\frac{\sigma_{1}}{\sigma_{2}}\right|^{n}
$$

The stress exponent value can then be determined using, 
$n=\frac{\ln \left(\frac{\dot{\varepsilon}_{Z 1}}{\dot{\varepsilon}_{Z 2}}\right)}{\ln \left(\frac{\sigma_{1}}{\sigma_{2}}\right)}$

As explained in figure $3 \mathrm{a}$, the value of $n$ can be determined by the measurement of the $\dot{\theta}_{i}$ for different $\sigma_{i}$ at same $\theta$ and T.

\subsubsection{Determination of $Q$ based on sinter-forging}

For the determination of $Q$, equation (31) is considered developing the temperature dependent term $A$.

$\left|\dot{\varepsilon}_{Z}\right|=A_{0}(G) \frac{\exp \left(\frac{-Q}{R T}\right)}{T}(1-\theta)^{\frac{1-n}{2}}\left(\frac{2}{3 \varphi}+\frac{1}{9 \psi}\right)^{\frac{n+1}{2}}\left|\sigma_{Z}\right|^{n}$

For two die compaction tests at same $\theta, \sigma_{z}$ and different temperatures we have:

$\left|\frac{\dot{\varepsilon}_{Z 1}}{\dot{\varepsilon}_{Z 2}}\right| \frac{T_{1}}{T_{2}}=\frac{\exp \left(\frac{-Q}{R T_{1}}\right)}{\exp \left(\frac{-Q}{R T_{2}}\right)}=\exp \left(\frac{Q}{R T_{2}}-\frac{Q}{R T_{1}}\right)=\exp \left(\frac{Q}{R}\left(\frac{1}{T_{2}}-\frac{1}{T_{1}}\right)\right)$

$Q$ is determined by:

$Q=\frac{R \ln \left(\frac{\dot{\varepsilon}_{Z 1} T_{1}}{\dot{\varepsilon}_{Z 2} T_{2}}\right)}{\left(\frac{1}{T_{2}}-\frac{1}{T_{1}}\right)}$

The value of $Q$ can be determined by the measurement of $\dot{\theta}_{i}$ for different $T_{i}$ at same $\theta$ and $\sigma_{z}$ (see figure $3 b$ ). 
a) $n$ EXPONENT IDENTIFICATION
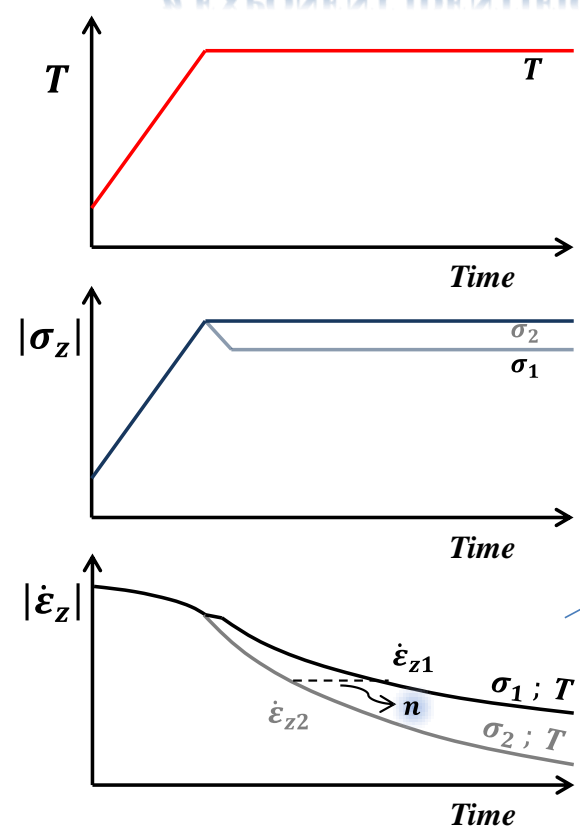

b) ACTIVATTION ENERGY IDENTTITICATION

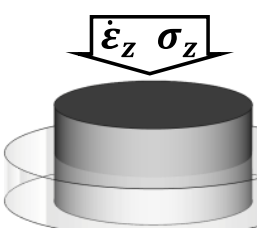

Sinter-forging

$$
\begin{gathered}
n=\frac{\ln \left(\frac{\dot{\varepsilon}_{z 1}}{\dot{\varepsilon}_{z 2}}\right)}{\ln \left(\frac{\sigma_{1}}{\sigma_{2}}\right)} \\
Q=\frac{R \ln \left(\frac{\dot{\varepsilon}_{z 1}}{\dot{\varepsilon}_{z 2}} \frac{T_{1}}{T_{2}}\right)}{\left(\frac{1}{T_{2}}-\frac{1}{T_{1}}\right)}
\end{gathered}
$$

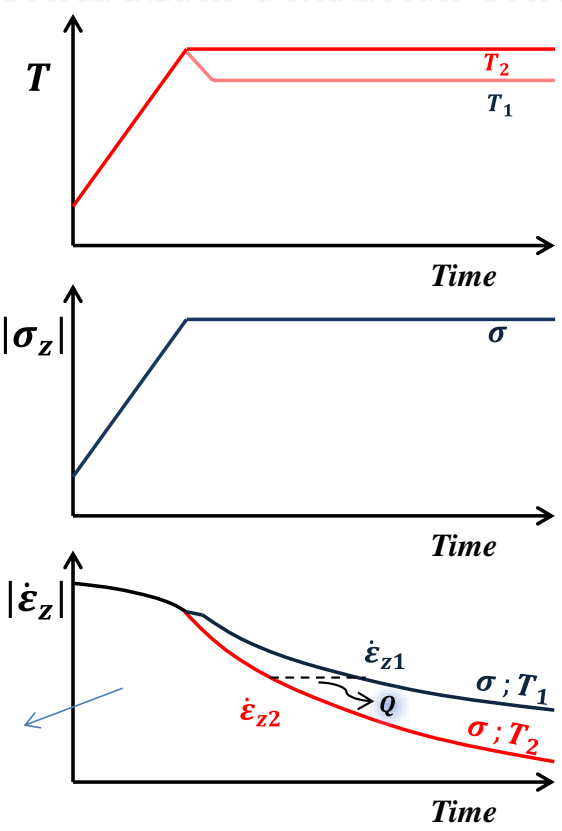

Figure 3 Sinter-forging based identification method for the creep law (a) exponent $n$ and $(b)$ activation energy $Q$.

\subsection{Determination of $A, \varphi$ and $\psi$}

With the knowledge of the stress exponent $n$, three unknown parameters remain $(A, \varphi$ and $\psi)$ for identifying an isothermal sintering model. Gathering the analytic formulas for sinterforging (31 and 37) and die compaction (18), the following system of equation can be defined.

$$
\left\{\begin{array}{lr}
\left(\frac{2}{3 \varphi}+\frac{1}{9 \psi}\right) A(T, G)^{\frac{2}{n+1}}=\left|\dot{\varepsilon}_{z}\right|^{\frac{2}{n+1}}\left|\sigma_{z}\right|^{\frac{-2 n}{n+1}}(1-\theta)^{\frac{n-1}{n+1}}=F_{Z} & \text { axial sinterforging }(45) \\
\left(\frac{1}{3 \varphi}-\frac{1}{9 \psi}\right) A(T, G)^{\frac{2}{n+1}}=\dot{\varepsilon}_{r}\left|\dot{\varepsilon}_{z}\right|^{\frac{1-n}{n+1}}\left|\sigma_{z}\right|^{\frac{-2 n}{n+1}}(1-\theta)^{\frac{n-1}{n+1}}=F_{r} & \text { Radial sinter }- \text { forging (46) } \\
\left(\psi+\frac{2}{3} \varphi\right) A(T, G)^{\frac{-2}{n+1}}=\left|\dot{\varepsilon}_{z}\right|^{\frac{-2}{n+1}}\left|\sigma_{z}\right|^{\frac{2 n}{n+1}}(1-\theta)^{\frac{1-n}{n+1}}=S P S & \text { die compaction (47) }
\end{array}\right.
$$

In the above system of equation, the left terms are the unknown parameters and the right terms are experimentally measurable responses of each respective test. Due to the form of equations (45-47), the elimination of $A$ for identifying the moduli is easy; however, the independent determination of $A$ is difficult. To circumvent this issue, the solution selected in this paper will be to combine equation (45) and (47) on a single instrumented experimental sinter-forging test to eliminate the bulk modulus $(\psi)$ and develop porosity function of the shear modulus $(\varphi)$. This method is explained in the section below. 


\subsubsection{Radial/axial sinter-forging based approach for determining $A$ and $\varphi$}

Both sinter-forging equations (45) and (47), have the term $1 /(9 \psi)$ that can be isolated and eliminated obtaining:

$F_{Z}-\frac{2 A^{\frac{2}{n+1}}}{3 \varphi}=-F_{r}+\frac{A^{\frac{2}{n+1}}}{3 \varphi}$

and then,

$\varphi=\frac{A(T, G)^{\frac{2}{n+1}}}{\left(F_{z}+F_{r}\right)}$

Developing, the term $F_{z}+F_{r}$ based on equations (45) and (47), we obtain,

$F_{z}+F_{r}=\left|\sigma_{z}\right|^{\frac{-2 n}{n+1}}(1-\theta)^{\frac{n-1}{n+1}}\left(\left|\dot{\varepsilon}_{z}\right|^{\frac{2}{n+1}}+\dot{\varepsilon}_{r}\left|\dot{\varepsilon}_{z}\right|^{\frac{1-n}{n+1}}\right)$

Inserting (50) in (49), we obtain,

$\varphi=A(T, G)^{\frac{2}{n+1}} \frac{\left|\sigma_{z}\right|^{\frac{2 n}{n+1}}(1-\theta)^{\frac{1-n}{n+1}}}{\left(\left|\dot{\varepsilon}_{z}\right|^{\frac{2}{n+1}}+\dot{\varepsilon}_{r}\left|\dot{\varepsilon}_{z}\right|^{\frac{1-n}{n+1}}\right)}$

From Abouaf et al $[14,17]$, the shear modulus fitting function can be defined by the following function of the porosity, where $\theta_{c}$ is the critical porosity where the shear modulus tends to zero at the initial stage.

$\varphi=\left(1-\frac{\theta}{\theta_{c}}\right)^{\mu}$

The value of $\theta_{c}$ should be closed to the initial porosity $\left(\theta_{\text {green }}\right)$. However, to avoid starting with a singularity ( $\varphi \rightarrow 0$ at the beginning) a slightly higher value is taken $\left(\theta_{c}=\theta_{\text {green }}+\right.$ 0.1 ) to ensure computation stability. There are very few studies in the literature on experimental identification of the moduli without theoretical reductive hypothesis $[15-17,20-$ 22,36,37]. A selection of four experimental shear modulus ("astroloy"[17], alumina[16], titanium aluminide[22], nickel[21]) are reported in figure $4 \mathrm{a}$. Taking a critical porosity of 0.4 , the fitting equation (52) demonstrates a good prediction of all experimental moduli. 

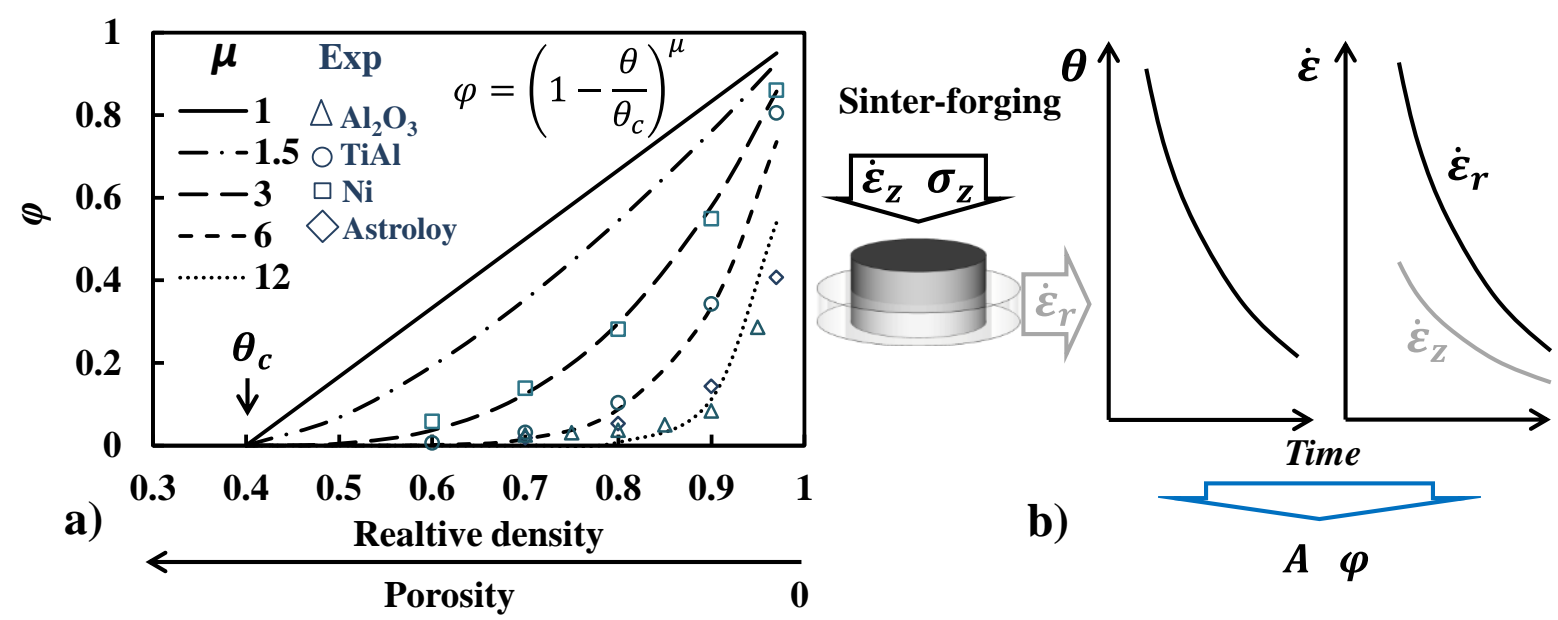

Figure 4 a) Representation of the shear modulus fitting equation compared to literature experimental data, $b$ ) Representation of characteristic sinter-forging equations required to identify the shear modulus and A parameters.

Combining equation (51) and the shear modulus fitting equation (52), we obtain,

$$
\left(1-\frac{\theta}{\theta_{c}}\right)^{\mu}=A(T, G)^{\frac{2}{n+1}} \frac{\left|\sigma_{z}\right|^{\frac{2 n}{n+1}}(1-\theta)^{\frac{1-n}{n+1}}}{\left(\left|\dot{\varepsilon}_{z}\right|^{\frac{2}{n+1}}+\dot{\varepsilon}_{r}\left|\dot{\varepsilon}_{z}\right|^{\frac{1-n}{n+1}}\right.}
$$

Latter equation can be reorganized to identify $A$ and $\varphi$ (indirectly identified by $\mu$ ) via the linear regression below equation left term $v s \frac{(n+1)}{2} \ln \left(1-\frac{\theta}{\theta_{c}}\right)$ and the data (figure $4 \mathrm{~b}$ ).

$$
-\frac{(n+1)}{2} \ln \left(\frac{\mid \sigma_{Z} \frac{2 n}{n+1}(1-\theta)^{\frac{1-n}{n+1}}}{\left(\left|\dot{\varepsilon}_{z}\right|^{\frac{2}{n+1}}+\left.\left.\dot{\varepsilon}_{r}\right|_{\dot{\varepsilon}_{z}}\right|^{\frac{1-n}{n+1}}\right.}\right)=\ln (A(T, G))-\mu\left(\frac{(n+1)}{2} \ln \left(1-\frac{\theta}{\theta_{c}}\right)\right)
$$

In isobar and isotherm conditions, equation (54) gives a straight line. However, as the parameter $A$ depends also on the grain size, disturbances may happen at the onset of grain growth. It is then recommended to conduct this identification in a stable zone of the intermediate stage to determine $\mu$, after that, the evolution of $A$ with grain size can be investigated if wished. If a slight grain growth is active at intermediate stage, it is possible to include this phenomenon by developing the creep term in (54) as $A(T, G)=A(T)\left(\frac{G_{0}}{G}\right)^{m}$ with $m=3$ for grain boundary diffusion. For zirconia, the grain size shows a plateau up to $97 \%$ of densification[35]. 


\subsubsection{Identification of $\psi$}

Knowing $A, n$ and $\varphi$, the bulk modulus $\psi$ can be identified using the ratio of equations (45) and (46).

$\frac{\frac{2}{3 \varphi}+\frac{1}{9 \psi}}{\frac{1}{3 \varphi}-\frac{1}{9 \psi}}=\frac{F_{Z}}{F_{r}}=\frac{\left|\dot{\varepsilon}_{Z}\right|^{\frac{2}{n+1}}}{\dot{\varepsilon}_{r}\left|\dot{\varepsilon}_{Z}\right|^{\frac{1-n}{n+1}}}=\left|\dot{\varepsilon}_{z}\right|\left|\dot{\varepsilon}_{r}\right|^{-1}$

After developments, we obtain the equation of the ratio of the shear and bulk moduli.

$\frac{\psi}{\varphi}=\frac{3}{9}\left(\frac{-\left|\dot{\varepsilon}_{z}\right|\left|\dot{\varepsilon}_{r}\right|^{-1}-1}{2-\left|\dot{\varepsilon}_{z}\right|\left|\dot{\varepsilon}_{r}\right|^{-1}}\right)$

This equation allows obtaining the bulk modulus from sinter-forging axial/radial measurements.

Alternatively, it is possible to use the die pressing analytical equation (47) to determine the bulk modulus by :

$\psi=A(T, G)^{\frac{2}{n+1}}\left|\dot{\varepsilon}_{Z}\right|^{\frac{-2}{n+1}}\left|\sigma_{z}\right|^{\frac{2 n}{n+1}}(1-\theta)^{\frac{1-n}{n+1}}-\frac{2}{3} \varphi$

This method using equations (45-47) assumes the applied stress is the dominant effect otherwise the bulk modulus $(\psi)$ cannot be eliminated using equations (38) and (39). A high pressure needs to be applied for this method. If the pressure is limited, a minimization method based on equations (38) and (39) should be preferred instead.

\section{Experiment and method}

The methodology employed in this paper includes the identification of the creep parameters $n$ and $Q$ by die compaction at different pressures (63 $\mathrm{MPa}$ and $89 \mathrm{MPa})$ and temperature $\left(1085^{\circ} \mathrm{C}, 1135^{\circ} \mathrm{C}\right.$ and $\left.1175^{\circ} \mathrm{C}\right)$ dwell. The method is described in figure 2; more details on the conditions will be specified in the results section. The SPS device "FCT system HPD25" is used in $10 \mathrm{~mm}$ inner die for die compaction and $15 \mathrm{~mm}$ for sinter-forging configuration. Interrupted $10 \mathrm{~mm}$ inner die compaction test was employed to produce the $10 \mathrm{~mm}$ diameter, $3.4 \mathrm{~mm}$ height porous samples placed in the sinter-forging $15 \mathrm{~mm}$ die. This way, the initial 
pre-sintered powder state is closer to the SPS conditions (without the disturbances from surface diffusion like in pressure-less sintering). The sinter-forged specimens have a dimension change of about $-25 \%$ of the initial height and $+5 \%$ of the initial diameter. The die compaction and sinter-forging configurations are similar to those in ref [21]. For the sinterforging experiment, a graphite foil has been added at the contact interface for minimizing the friction[31] and the barrel effect it may generate (not observed in our tests). The specimen temperature was taken by a K-type thermocouple near the edge of the specimen (directly on the graphite foil for the die compaction and directly on the specimen for the sinter-forging configuration). Zirconia "Tosoh TZ-3Y-E"powder was used for this study. This powder as a specific surface area of $16 \mathrm{~m}^{2} \mathrm{~g}^{-1}$ and an actual particle size of $40 \mathrm{~nm}$. The SEM[38] and TEM[39] analysis confirm the presence of $40 \mathrm{~nm}$ crystallites in $167 \mathrm{~nm}$ soft agglomerates. The determination of $A, \varphi$ and $\psi$ with the sinter-forging method presented in figure $4 \mathrm{~b}$ was done for the temperatures $1085^{\circ} \mathrm{C}$ and $1135^{\circ} \mathrm{C}$. The main difficulty of this test was to obtain the information of the radial displacement (diametric extension during the test). Without specific instrumentation to measure this displacement, numerous experiments were done at different isobar isotherm sinter-forging holding times. The determination of these sinterforging radial displacement curves was the longest experimental work and takes 11 tests for the two temperatures. For the sinter-forging tests, the radial extension data were used to calculate the axial stress evolution. After knowing all sintering parameters $n, A, \varphi$ and $\psi$, the modeling of SPS experiments in die compaction was done. A final adjustment of the sinterforging linear curves by equation (54) and SPS modeled curves is performed to obtain a model explaining all configurations results. 


\section{Results and discussions}

In this section, the die compaction based identification of the creep parameters is presented first. Then, the sinter-forging based identification of the sintering moduli and the final modeling of SPS test will be presented.

\subsection{Identification of the $n$ and $Q$ creep law parameters}

The method presented in section 2.3 and figure 2 is based on isothermal die compaction tests to identify the parameter $n$ with equation (22) at different pressures (figure 2a) and $Q$ with equation (26) at different temperatures (figure 2b). The SPS die compaction tests are reported in figure 5. The test at $5 \mathrm{kN}$ corresponds to $63 \mathrm{MPa}$ and those at $7 \mathrm{kN}$ corresponds to $89 \mathrm{MPa}$. In order to calculate the porosity elimination rate needed by equations (22) and (26) a fitting mathematical equation of the following form was employed.

$\theta_{f i t}=a-(b * \ln (t+c))$

With the porosity elimination rate curves (on the right of figure 5), the "jump" in the rate curves is taken at the same porosity value between two applied stresses at the same temperature (to calculate $n$ ) or two temperatures at the same stress (to calculate $Q$ ). The matching zones of identification of $n$ and $Q$ are reported in figure 5.

The identified parameters are reported in figure $6 \mathrm{a}$ for $n$ and figure $6 \mathrm{~b}$ for $Q$. An average $n$ stress exponent of 1.98 is measured. This value close to 2 can be associated with a grain boundary sliding mechanism[27]. Similar values were obtained by Bernard-Granger and Guizard [35] at the temperatures $950^{\circ} \mathrm{C}, 1000^{\circ} \mathrm{C}$ and $1050^{\circ} \mathrm{C}$. Concerning the activation energy, the values are distributed around $500 \mathrm{~kJ} / \mathrm{mol}$ with a high dispersion. Bernard-Granger and Guizard [35] have found $450 \mathrm{~kJ} / \mathrm{mol}$. In the red zone (figure $6 \mathrm{~b}$ ), the values of the activation energies are calculated in a zone below 0.2 of porosity and with a couple of temperatures including $1175^{\circ} \mathrm{C}$. At these temperatures and for closed porosity, the grain growth may be active and disturb the identification process (using equation (26)) where the 
grain size is supposed similar for each couple of porosity. The couple of temperatures $1085^{\circ} \mathrm{C}-1135^{\circ} \mathrm{C}$ at porosities higher than 0.2 is considered more accurate and gives average activation energy of $400 \mathrm{~kJ} / \mathrm{mol}$, a value relatively close to the $450 \mathrm{~kJ} / \mathrm{mol}$ of BernardGranger and Guizard [35].
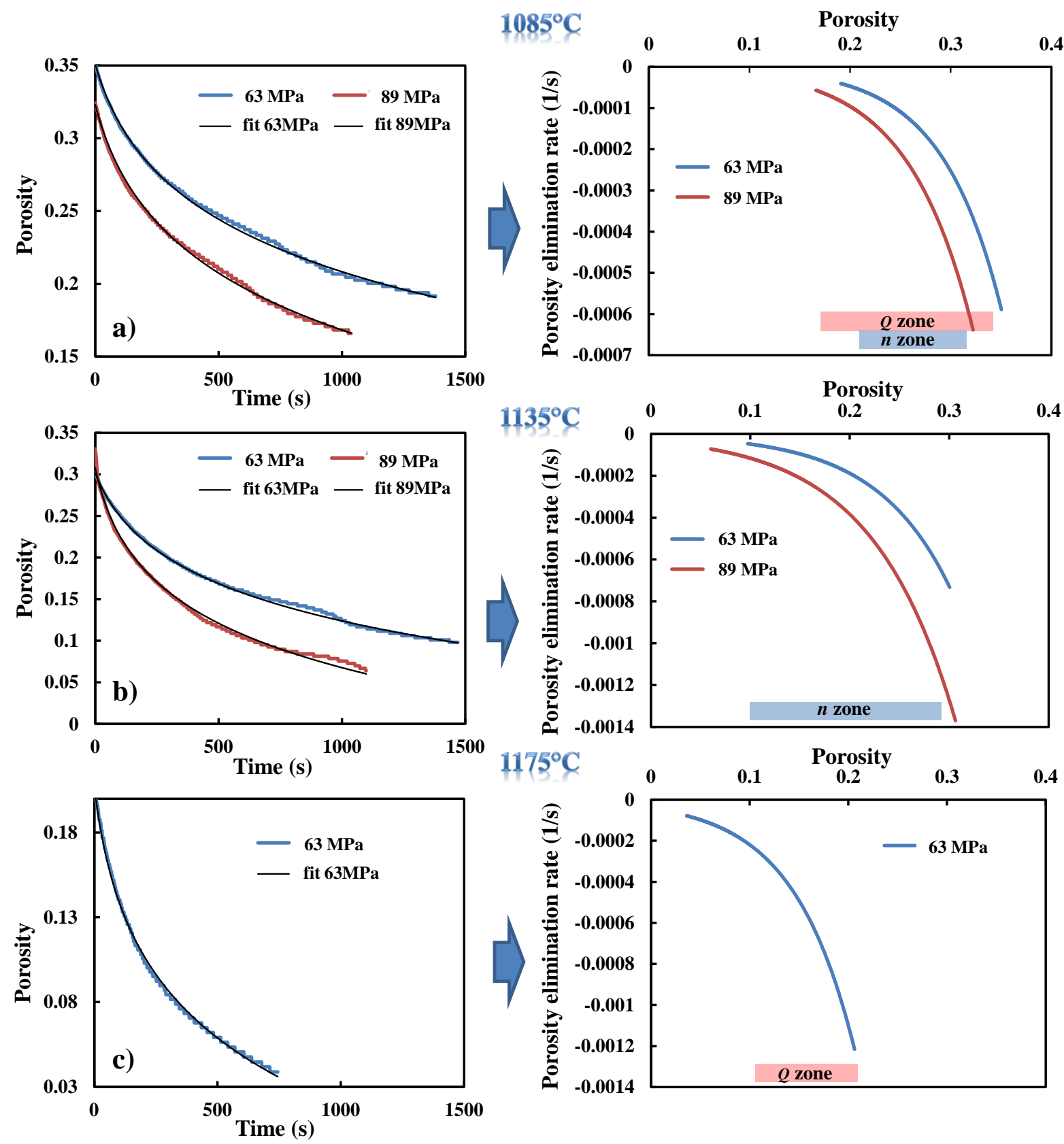

Figure 5 SPS isobar isotherm die compaction tests at a) $\left.\left.1085^{\circ} \mathrm{C}, \mathrm{b}\right) 1135^{\circ} \mathrm{C}, \mathrm{c}\right) 1175^{\circ} \mathrm{C}$, the porosity curves are represented on the left and the porosity elimination rate are reported on the right.

The last noticeable aspect is the porosity dependence of $n$ and $Q$. This seems to suggest a slow change of mechanism from diffusion $(n=1)$ at high porosity to dislocation motion $(n=3)$ at low porosity. However, this slow tendency should be the opposite considering the stress 
intensification phenomenon is high for high porosity values [27]. For the activation energy in the red zone figure $6 \mathrm{~b}$, the tendency is inverted and seems not pertinent. This tendency may be explained by a non-equilibrium specimen temperature where at the beginning of the holding, the temperature at the edge of the specimen can be slightly hotter than the whole specimen temperature. If the specimen temperature is gradually homogenized, the similar tendency of the one shown in figure 6 can be observed. The advantage of the present identification method is to explore the mechanism of evolution at different temperatures and porosity ranges. However, the high temperature sensitivity of SPS [40] need to be considered. Despite the main grain growth onset is located at porosity closed to 0.05 for zirconia [35], a slow grain growth evolution in the submicronic range may also slightly disturb this identification such as a potential impact of differential pore coarsening by surface diffusion [25]. A similar phenomenon is observed for the Wang and Raj method [41] for pressureless sintering. In the latter, the sintering activation energy is identified at different porosities, a porosity dependence of $Q$ is often observed[42-44] due to grain growth disturbance, pore coarsening and experimental discrepancies. In general, an average value of $Q$ is taken, the same is applied here for $n$ and $Q$.
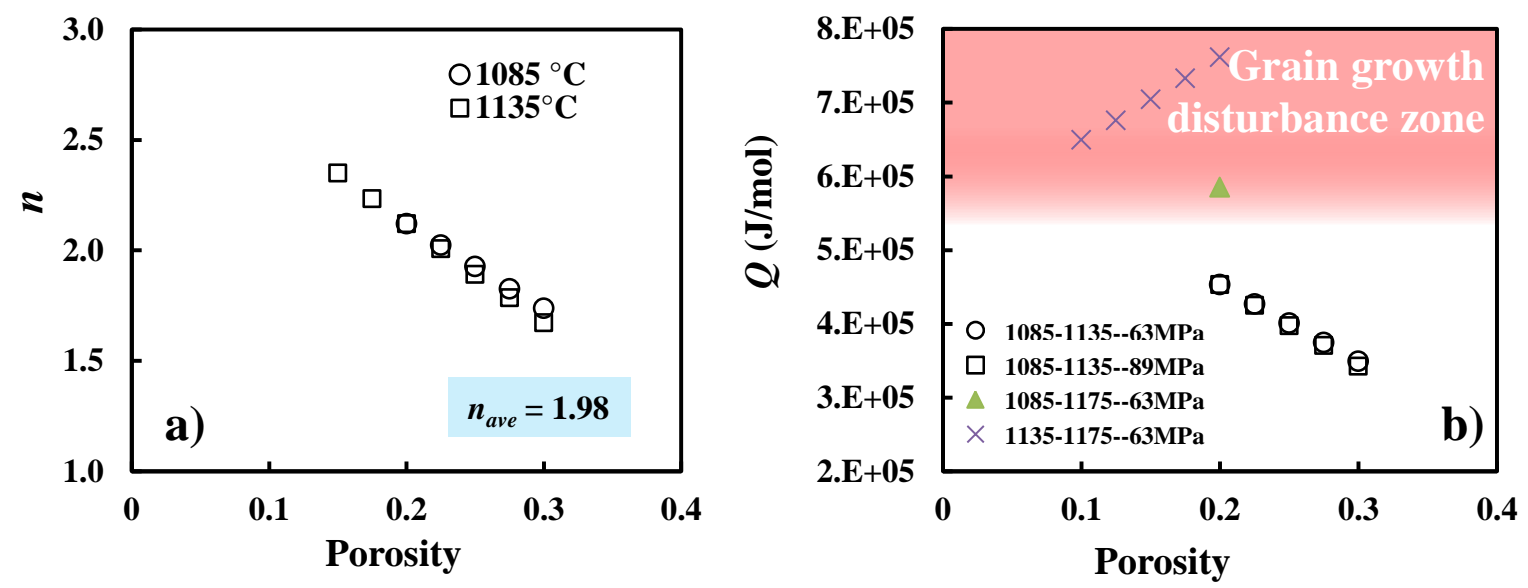

Figure 6 Die compaction based creep law identification of a) $n$ and $b$ ) $Q$, the couple of identification of $Q$ is named as T1-T2-P. 


\subsection{Identification of $A, \varphi$ and $\psi$ by sinter-forging}

The determination of the moduli was the most difficult experimental task as equation (54) requires the experimental determination of $\dot{\varepsilon}_{r}, \dot{\varepsilon}_{z}, \theta$. The results of the experiments at $1085^{\circ} \mathrm{C}$ and $1135^{\circ} \mathrm{C}$ are reported in figure 7. Numerous interrupted sinter-forging experiments were done to obtain the information of the diametric expansion. A mathematical fitting curve (see below equation) have been used to determine unique average curves for $\dot{\varepsilon}_{r}, \dot{\varepsilon}_{z}, \theta$.

Diameter $_{\text {fit }}=a+(b * \ln (t+c))$
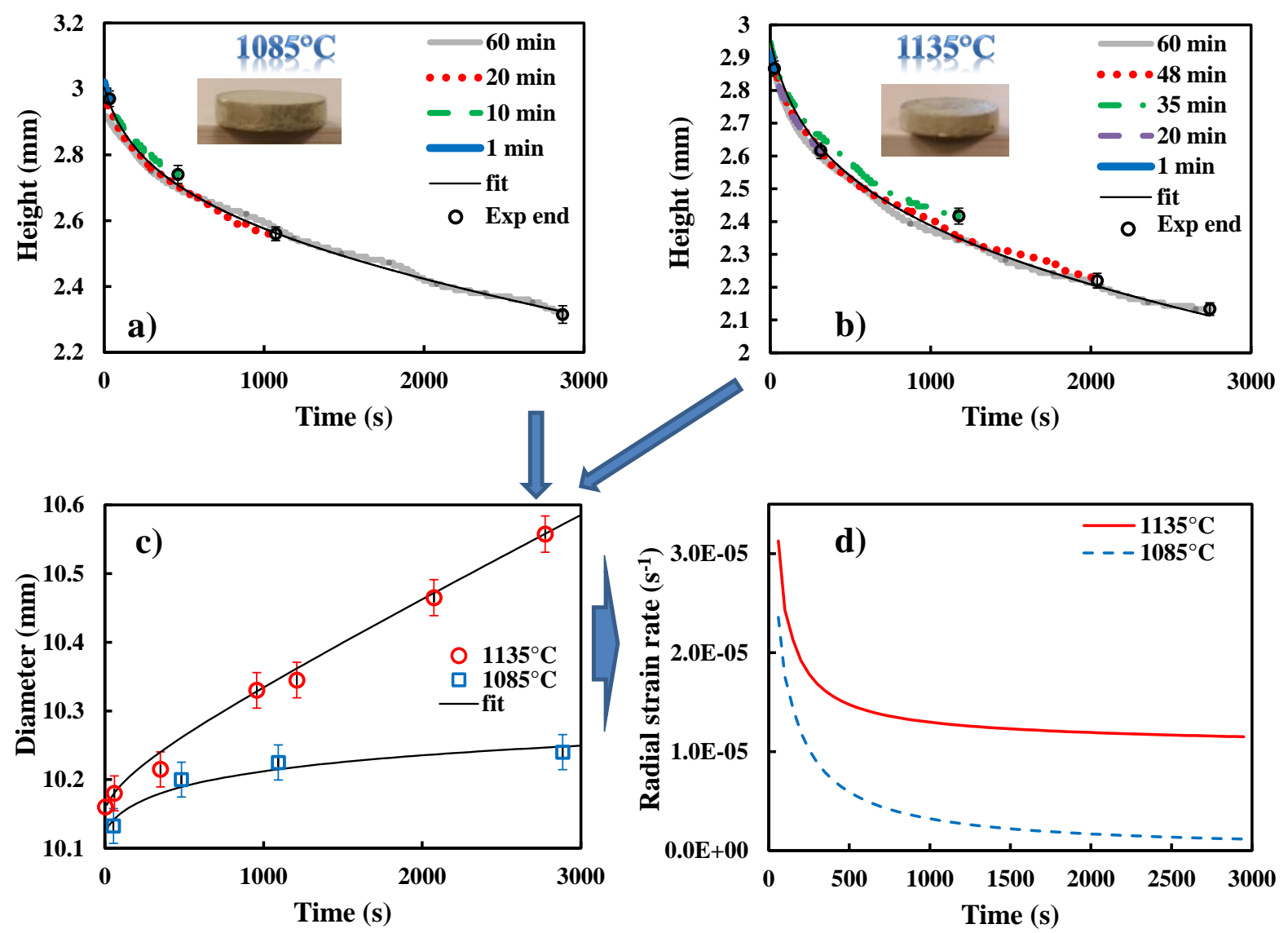

Figure 7 Sinter-forging experimental results for obtaining the height evolution at a) $1085^{\circ} \mathrm{C}$, b) $\left.1135^{\circ} \mathrm{C}, c\right)$ the specimen diameter expansion and via a fitting curve, $d$ ) the radial strain rate at both temperatures.

With figure 7 experimental data, the linear regression equation (54) can be used at $1085^{\circ} \mathrm{C}$ and $1135^{\circ} \mathrm{C}$ using $\theta_{c}=0.6$. The two curves are reported in figure $8 \mathrm{a}$ where the slope gives $\mu$ and the origin gives $\ln (A)$. The noise on these curve reflect the $1 \mathrm{kN}$ spikes randomly generates by the load cell close to the lower limit. This noise on the force signal is considered 
in the model and represents an error of $2 \%$ due to the "rate-dependent" nature of creep based sintering behavior at high temperature which mitigates the effect of the noise on the force curve. Despite The shear modulus $\varphi$ can be determined knowing $\theta_{c}$, and taking the exponent of the origin, the value of $A(T)$ for each temperature can be determined. Knowing the shear modulus $\varphi$, the bulk modulus $\psi$ can be determined via equation (56). The results are reported in figure $8 \mathrm{~b}$ and we can see the moduli identified at the two temperatures converge to the same curve which depends on the relative density. For this powder, the temperature has no effect on the moduli.

At this stage, all sintering model parameters are determined, the model can be verified by simulating the die pressing sintering response at $1085^{\circ} \mathrm{C}$ and $1135^{\circ} \mathrm{C}$ using the data of figure $5 \mathrm{a}$ and $5 \mathrm{~b}$. In order to obtain the optimal model accuracy (reduces the disturbances of the temperature gradients), an adjustment of the modeling parameter has been done between figure $8 \mathrm{a}$ and the die pressing modeled curves figure $8 \mathrm{c}$ and $8 \mathrm{~d}$. Consequently, the matching of the model and experimental data is not ideal in figure $8 \mathrm{a}, 8 \mathrm{~b}$ and $8 \mathrm{c}$ but the model represents the optimal solution between the sinter-forging and die pressing configurations. Concerning the discrepancy at $1085^{\circ} \mathrm{C}$ in figure $8 \mathrm{a}$, it was shown in $[35,39]$ that the nanozirconia powder may be subjected to a pre-coarsening stage at temperature closed to $1000^{\circ} \mathrm{C}$. This may explain the slight non-linearity phenomenon at $1085^{\circ} \mathrm{C}$ as the parameter $A$ depends on the grain size. Nevertheless, the error on modeled SPS curves (figure 8c) is less than 3\%, which is a very satisfactory result considering the way the parameters have been identified (sinter-forging tests). The direct regression methods have a higher accuracy because their theoretical moduli limit the numbers of variable to identify, but their domain of application is quite limited. In comparison, the present method employs minimal theoretical hypotheses and identifies all parameters (creep and moduli) directly from the porous stage (without grain size disturbance). Therefore, the resulting parameters are valid in a wide range of porosity and configurations. 


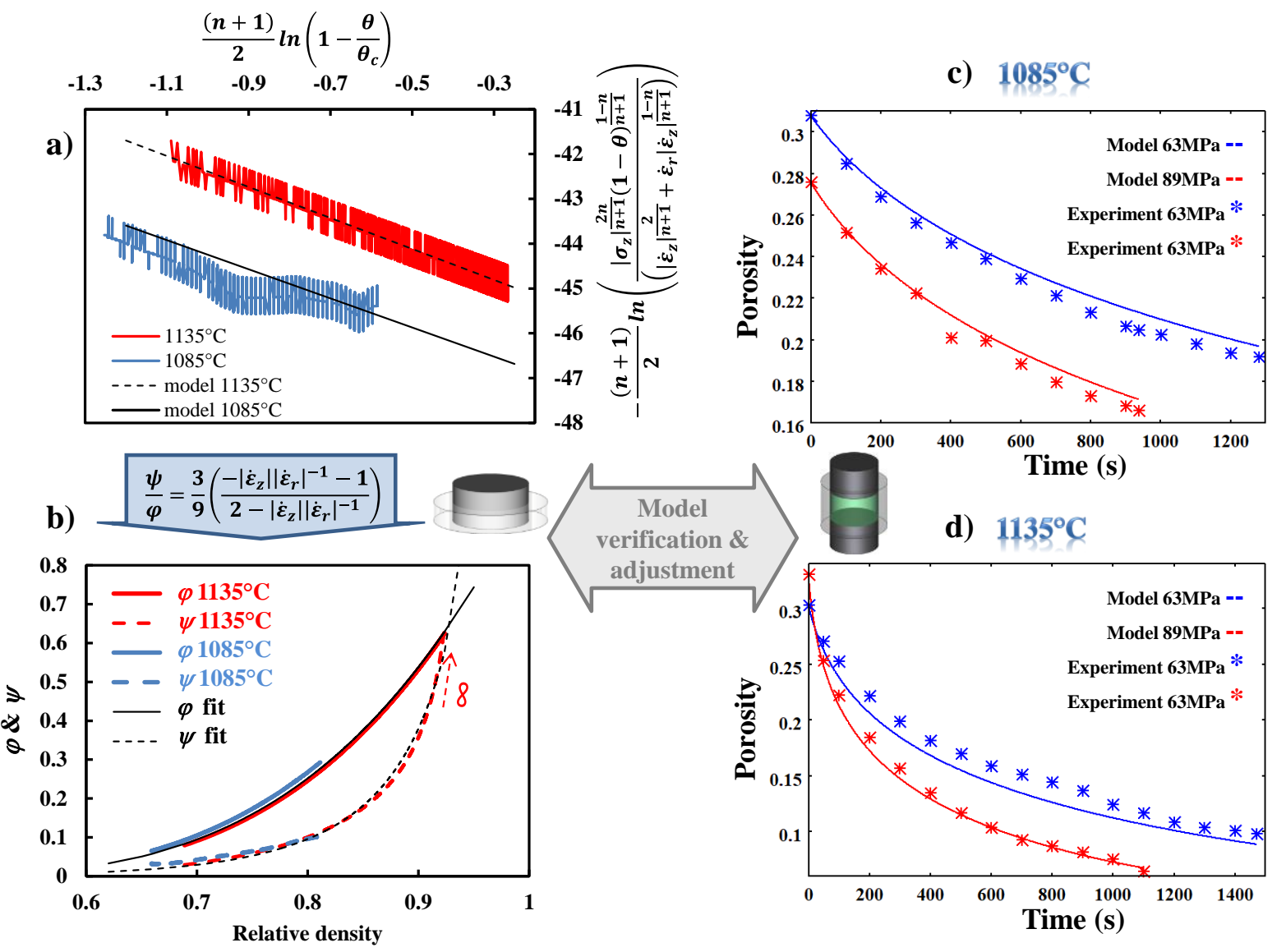

Figure 8 Experimental identification of $A, \varphi$ and $\psi$, a) sinter-forging linear regression of obtaining $A$ and $\varphi, b)$ determination of $\psi, c$ ) validation by modeling the die pressing porosity evolution at $1085^{\circ} \mathrm{C}$ and d) $1135^{\circ} \mathrm{C}$; optimal modeling parameters are identified by adjusting the sinter-forging and die pressing model curves.

After the optimization, two values of $A$ are obtained. Based on equation (2), it is possible to estimate $A_{0}$ and $Q$ by plotting $\ln (A T)$ function of $1 / R T$ (see figure 9 ). An activation energy of $536 \mathrm{~kJ} / \mathrm{mol}$ is obtained, this value is higher than the $400 \mathrm{~kJ} / \mathrm{mol}$ obtained in figure 6 for the same temperature range. However, only two points are taken and the modeling curves were adjusted. If an instrumented sinter-forging test is developed to avoid the time consuming interrupted tests, several temperatures can be easily done and a more precise temperature dependence can be estimated. 


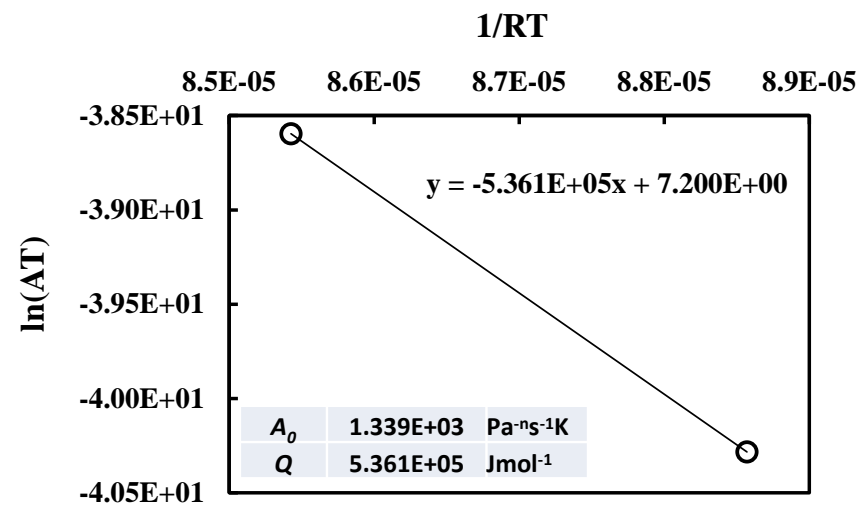

Figure 9 Estimation of the temperature dependence of A.

Finally, this method succeeds to identify the shear and bulk moduli directly from porous mechanical testing. The experimentally identified moduli are detailed below.

$\varphi=\left(1-\frac{\theta}{0.6}\right)^{3.4}$

$\psi=0.07 \frac{(1-\theta)^{5.8}}{\theta}$

These experimental moduli have been compared to the theoretical and experimental values of the literature in figure 10. In this plot, the blue arrow indicates the displacement of the curves from the theoretical moduli (green and red curves) having a higher value than the experimental moduli. For the bulk modulus, the behavior of large spherical particles like Ti6Al4V $(\sim 100 \mu \mathrm{m})$ indicates the importance of the initial stage critical porosity implying $\psi \rightarrow 0$. In general ${ }_{2}$ the initial stage is poorly described by the theoretical models without the initial particle contact effect. 

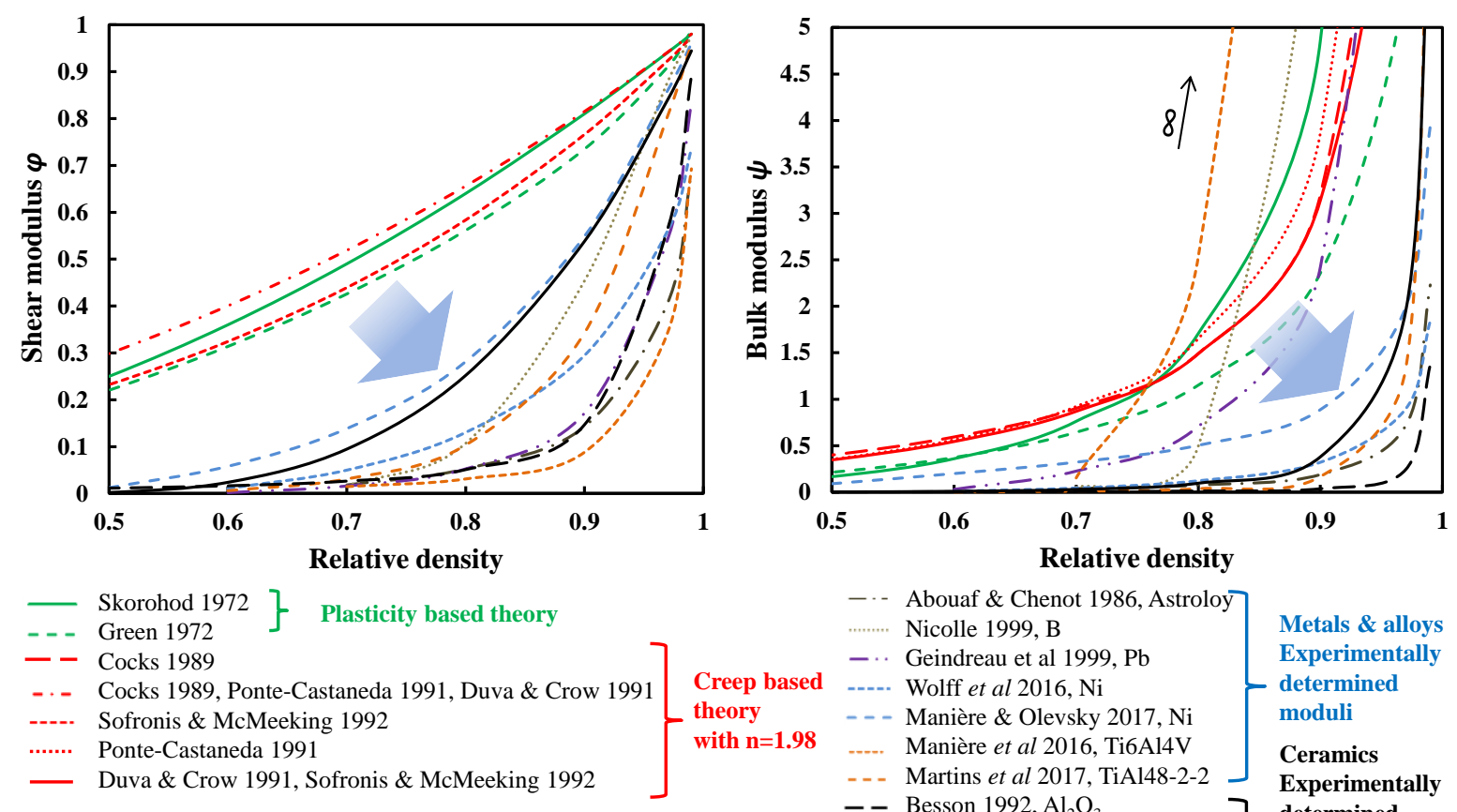

$\left.\begin{array}{ll}- & \text { Skorohod 1972 } \\ --- & \text { Green } 1972 \\ -- & \text { Cocks 1989 } \\ -.- & \text { Cocks 1989, Ponte-Castaneda 1991, Duva \& Crow 1991 } \\ ---.- & \text { Sofronis \& McMeeking } 1992 \\ \ldots . . . . & \text { Ponte-Castaneda 1991 } \\ - & \text { Duva \& Crow 1991, Sofronis \& McMeeking } 1992\end{array}\right]$

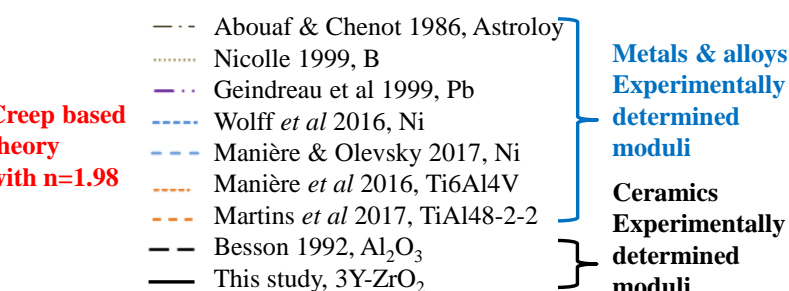

Figure 10 Identified moduli compared with literature moduli from creep[79,45]/plasticity[6,46] based theory and experimental identification for metals[15,18,19,21,37], alloys[20,22,47] and ceramics[16].

\section{Conclusion}

In this study, we present a comprehensive formulation of the continuum theory of sintering for the direct identification of the shear and bulk moduli and the creep behavior from the porous stage. This approach addresses the challenge of dissimilar creep behavior at porous and fully dense stages preventing the identification of ceramics sintering modeling parameters due to final stage grain growth. In this approach, all the temperature/grain size dependent creep parameters and the porous dependent shear and bulk moduli are identified combining die pressing and several interrupted sinter-forging tests at high temperatures and pressures.

One of the main challenges of this identification methodology was to conduct numerous interrupted sinter-forging tests to obtain the axial/radial evolution required to distinguish the shear and bulk powder behavior during the sintering. However, this time consuming sinterforging tests can be highly simplified if an external instrumentation is developed to in situ 
measure the radial expansion. With such instrumentation, a wider temperatures range can be easily conducted. This method will allow exploring the following prospects:

- the effects of temperature, pressure and porosity on the sintering behavior,

- the grain size effect on the sintering trajectories at the final stage,

- the impact of heating rates, electrical current/field on the sintering behavior,

- the study of flash spark plasma sintering behavior compared to conventional behavior,

- metals and allows may also need this method if important microstructural changes or phase transition/reaction occur during the densification preventing using fully dense creep tests like in ceramics.

\section{Appendix: discussion on the link between solid state and continuum sintering models.}

The pressure assisted sintering theory involves different creep based mechanisms. Solid state hot pressing model has the following equation[27].

$\frac{1}{\rho} \frac{d \rho}{d t}=\frac{H D(T) \phi(\rho)^{n} \sigma_{Z}^{n}}{G^{m} k T}$

The exponent $n$ and $m$ of this equation may have different values depending on the underlying creep mechanism : $n=1, m=2$, for lattice diffusion, $n=1, m=3$ for grain boundary diffusion, and $n=1$ or 2, $m=1$ for grain boundary sliding, $n>3, m=0$ for dislocation based creep.

In theoretical approaches like the sintering map[48,49], each sintering mechanisms are considered and zones of dominant mechanisms are identified. For oxide ceramics, the strong chemical bonding limits the dislocation motion (unless pressures over GPa is employed[48,50]) and makes the diffusion mechanisms dominant. The grain boundary sliding is generally associated with diffusion for hot pressing as it follows the grain deformation. In practice, equation (62) is considered for the identification of the dominant sintering 
mechanism. The same is done for the experimental identification by the continuum model (18).

For metal, the question of primarily creep can be considered. Primarily creep is generally associated with dislocation hardening mechanisms. This effect can be characterized by SPS multistep forging on fully dense samples[15,20,22]. For ceramics, this dislocation phenomenon can be reasonably neglected.

Another simplification of the model concerns the anisotropy of the model. In hot pressing the grain are slightly flattened by the absence of radial displacement. As this anisotropy is limited and quickly disappears with the grain growth, this contribution is generally neglected. In the sinter-forging experiments where the grain can be significantly deformed, the radial extension was only $4 \%$ of the initial diameter so the grain anisotropy was not studied. For experiment with significant radial displacement (like in metals), the question of anisotropy may be considered by comparing the results with Hot Isostatic Pressing (HIP) experiments. For the sintering of additive manufacturing materials having an architectured porosity, the anisotropy must by intrinsically considered[51].

The continuum model (10) is a model bridging solid state sintering model represented by equation (62) and the mechanics needed to simulate the sintering by stress and strain rate tensors. The continuum model is not different but inspired by the solid state sintering solutions. The analytical solution of the continuum model (18) can be compared to equation (62) from continuum model, we have $\phi=\left(\left(\psi+\frac{2}{3} \varphi\right)^{\frac{-n-1}{2}}(1-\theta)^{\frac{1-n}{2}}\right)^{\frac{1}{n}}$ and $A(T, G)=\frac{H D(T)}{G^{m} k T}$. The stress intensification factor $\phi$ is a porosity dependent function bridging all stages. In the combined stage sintering theory[52], it was shown that the geometrical parameters of the solid state models of each three sintering stages can be defined by a unique porosity function. This concept of free sintering is also applied to pressure assisted sintering giving a unique porosity function called the stress intensification factor $\phi$ [27]. In the continuum models, the latter must distinguish the shear and bulk underlying behavior to connect the tensors. 


\section{Acknowledgements}

The help and support of Jérôme Lecourt is gratefully acknowledged. The project region normadie - 00016601-20E02057_RIN RECHERCHE 2020 - Emergent - ULTIMODULUS support this study.

\section{References}

[1] J. Zhao, M.P. Harmer, Effect of Pore Distribution on Microstructure Development: III, Model Experiments, J. Am. Ceram. Soc. 75 (1992) 830-843. doi:10.1111/j.11512916.1992.tb04148.x.

[2] C. Manière, G. Lee, J. McKittrick, S. Chan, E.A. Olevsky, Modeling zirconia sintering trajectory for obtaining translucent submicronic ceramics for dental implant applications, Acta Mater. 188 (2020) 101-107. doi:10.1016/j.actamat.2020.01.061.

[3] J.A. Alvarado-Contreras, E.A. Olevsky, A.L. Maximenko, R.M. German, A continuum approach for modeling gravitational effects on grain settling and shape distortion during liquid phase sintering of tungsten heavy alloys, Acta Mater. 65 (2014) 176-184. doi:10.1016/j.actamat.2013.10.059.

[4] C. Manière, L. Durand, A. Weibel, C. Estournès, Spark-plasma-sintering and finite element method: From the identification of the sintering parameters of a submicronic $\alpha$ -alumina powder to the development of complex shapes, Acta Mater. 102 (2016) 169175. doi:10.1016/j.actamat.2015.09.003.

[5] R.K. Bordia, S.-J.L. Kang, E.A. Olevsky, Current understanding and future research directions at the onset of the next century of sintering science and technology, J. Am. Ceram. Soc. 100 (2017) 2314-2352. doi:10.1111/jace.14919.

[6] V.V. Skorohod, Rheological basis of the theory of sintering, Nauk. Dumka, Kiev. (1972).

[7] P. Sofronis, R.M. McMeeking, Creep of Power-Law Material Containing Spherical Voids, J. Appl. Mech. 59 (1992) S88. doi:10.1115/1.2899512.

[8] A.C.F. Cocks, Inelastic deformation of porous materials, J. Mech. Phys. Solids. 37 (1989) 693-715. doi:10.1016/0022-5096(89)90014-8.

[9] J.M. Duva, P.D. Crow, The densification of powders by power-law creep during hot isostatic pressing, Acta Metall. Mater. 40 (1992) 31-35. doi:10.1016/09567151(92)90196-L.

[10] C. Manière, L. Durand, G. Chevallier, C. Estournès, A spark plasma sintering densification modeling approach: from polymer, metals to ceramics, J. Mater. Sci. 53 (2018) 7869-7876. doi:10.1007/s10853-018-2096-8.

[11] C. Manière, E. Saccardo, G. Lee, J. McKittrick, A. Molinari, E.A. Olevsky, Swelling negation during sintering of sterling silver: An experimental and theoretical approach, Results Phys. 11 (2018) 79-84. doi:10.1016/j.rinp.2018.08.035.

[12] C. Wolff, S. Mercier, H. Couque, A. Molinari, Modeling of conventional hot 
compaction and Spark Plasma Sintering based on modified micromechanical models of porous materials, Mech. Mater. 49 (2012) 72-91. doi:10.1016/j.mechmat.2011.12.002.

[13] E. V. Aleksandrova, A.M. Ilyina, E.G. Grigoryev, E.A. Olevsky, Contribution of Electric Current into Densification Kinetics During Spark Plasma Sintering of Conductive Powder, J. Am. Ceram. Soc. 98 (2015) 3509-3517. doi:10.1111/jace.13816.

[14] M. Abouaf, PhD, Modélisation de la compaction de poudres métalliques frittées, approches par la mécanique des milieux continus, Institut national polytechnique de Grenoble, 1985.

[15] C. Nicolle, $\mathrm{PhD}$, Mise en forme de poudre de bore par compression isostatique à chaud: determination des propriétés rhéologiques et simulation numérique du procédé, Université de Bourgogne, France, 1999.

[16] J. Besson, M. Abouaf, Rheology of Porous Alumina and Simulation of Hot Isostatic Pressing, J. Am. Ceram. Soc. 75 (1992) 2165-2172. doi:10.1111/j.11512916.1992.tb04479.x.

[17] M. Abouaf, J.L. Chenot, G. Raisson, P. Bauduin, Finite element simulation of hot isostatic pressing of metal powders, Int. J. Numer. Methods Eng. 25 (1988) 191-212. doi:10.1002/nme.1620250116.

[18] C. Geindreau, D. Bouvard, P. Doremus, Constitutive behaviour of metal powder during hot forming. Part I: Experimental investigation with lead powder as a simulation material, Eur. J. Mech. - A/Solids. 18 (1999) 581-596. doi:10.1016/S09977538(99)00102-3.

[19] C. Geindreau, D. Bouvard, P. Doremus, Constitutive behaviour of metal powder during hot forming.: Part II: Unified viscoplastic modelling, Eur. J. Mech. - A/Solids. 18 (1999) 597-615. doi:10.1016/S0997-7538(99)00101-1.

[20] C. Manière, U. Kus, L. Durand, R. Mainguy, J. Huez, D. Delagnes, C. Estournès, Identification of the Norton-Green Compaction Model for the Prediction of the Ti-6Al4V Densification During the Spark Plasma Sintering Process, Adv. Eng. Mater. 18 (2016) 1720-1727. doi:10.1002/adem.201600348.

[21] C. Manière, E.A. Olevsky, Porosity dependence of powder compaction constitutive parameters: Determination based on spark plasma sintering tests, Scr. Mater. 141 (2017) 62-66. doi:10.1016/j.scriptamat.2017.07.026.

[22] D. Martins, F. Grumbach, C. Manière, P. Sallot, K. Mocellin, M. Bellet, C. Estournès, In-situ creep law determination for modeling Spark Plasma Sintering of TiAl 48-2-2 powder, Intermetallics. 86 (2017) 147-155. doi:10.1016/j.intermet.2017.03.006.

[23] C. Manière, L. Durand, A. Weibel, C. Estournès, A predictive model to reflect the final stage of spark plasma sintering of submicronic $\alpha$-alumina, Ceram. Int. 42 (2016) 92749277. doi:10.1016/j.ceramint.2016.02.048.

[24] G. Kerbart, C. Manière, C. Harnois, S. Marinel, Predicting final stage sintering grain growth affected by porosity, Appl. Mater. Today. $20 \quad$ (2020) 100759. doi:10.1016/j.apmt.2020.100759.

[25] E.A. Olevsky, S. Kandukuri, L. Froyen, Consolidation enhancement in spark-plasma sintering: Impact of high heating rates, J. Appl. Phys. 102 (2007) 114913. doi:10.1063/1.2822189.

[26] G. Kerbart, C. Manière, C. Harnois, S. Marinel, Master sintering curve with dissimilar grain growth trajectories: A case study on MgAl2O4, J. Eur. Ceram. Soc. 41 (2021) 1048-1051. doi:10.1016/j.jeurceramsoc.2020.09.003. 
[27] M.N. Rahaman, Sintering of Ceramics, CRC Press, 2007.

[28] R.M. German, Sintering Theory and Practice, Wiley, Wiley, 1996. http://www.wiley.com/WileyCDA/WileyTitle/productCd-047105786X.html.

[29] E.A. Olevsky, Theory of sintering: from discrete to continuum, Mater. Sci. Eng. R Reports. 23 (1998) 41-100. doi:10.1016/S0927-796X(98)00009-6.

[30] J. Chevalier, C. Olagnon, G. Fantozzi, H. Gros, Creep behaviour of alumina, zirconia and zirconia-toughened alumina, J. Eur. Ceram. Soc. 17 (1997) 859-864. doi:10.1016/S0955-2219(96)00160-4.

[31] C. Manière, L. Durand, C. Estournès, Powder/die friction in the spark plasma sintering process: Modelling and experimental identification, Scr. Mater. 116 (2016) 139-142. doi:10.1016/j.scriptamat.2016.01.040.

[32] J.E. Dorn, Some fundamental experiments on high temperature creep, J. Mech. Phys. Solids. 3 (1955) 85-116. doi:10.1016/0022-5096(55)90054-5.

[33] G. Lee, E.A. Olevsky, C. Manière, A. Maximenko, O. Izhvanov, C. Back, J. McKittrick, Effect of electric current on densification behavior of conductive ceramic powders consolidated by spark plasma sintering, Acta Mater. 144 (2018) 524-533. doi:10.1016/j.actamat.2017.11.010.

[34] O.. Sherby, J.. Lytton, J.. Dorn, Activation energies for creep of high-purity aluminum, Acta Metall. 5 (1957) 219-227. doi:10.1016/0001-6160(57)90169-4.

[35] G. Bernard-Granger, C. Guizard, Spark plasma sintering of a commercially available granulated zirconia powder: I. Sintering path and hypotheses about the mechanism(s) controlling densification, Acta Mater. 55 (2007) 3493-3504. doi:10.1016/j.actamat.2007.01.048.

[36] P. Mondalek, L. Silva, M. Bellet, A Numerical Model for Powder Densification by SPS Technique, Adv. Eng. Mater. 13 (2011) 587-593. doi:10.1002/adem.201000340.

[37] C. Wolff, S. Mercier, H. Couque, A. Molinari, F. Bernard, F. Naimi, Thermalelectrical-mechanical simulation of the nickel densification by Spark Plasma Sintering. Comparison with experiments, Mech. Mater. 100 (2016) 126-147. doi:10.1016/j.mechmat.2016.06.012.

[38] H.A. Tajiri, H.A. Al-Qureshi, Manufacturing and characterization of porous ceramic capillary membranes for enzyme functionalization through click chemistry, J. Brazilian Soc. Mech. Sci. Eng. 42 (2020) 170. doi:10.1007/s40430-020-2254-1.

[39] H. Majidi, T.B. Holland, K. van Benthem, Quantitative analysis for in situ sintering of $3 \%$ yttria-stablized zirconia in the transmission electron microscope, Ultramicroscopy. 152 (2015) 35-43. doi:10.1016/j.ultramic.2014.12.011.

[40] C. Manière, L. Durand, E. Brisson, H. Desplats, P. Carré, P. Rogeon, C. Estournès, Contact resistances in spark plasma sintering: From in-situ and ex-situ determinations to an extended model for the scale up of the process, J. Eur. Ceram. Soc. 37 (2017) 1593-1605. doi:10.1016/j.jeurceramsoc.2016.12.010.

[41] J. Wang, R. Raj, Estimate of the Activation Energies for Boundary Diffusion from Rate-Controlled Sintering of Pure Alumina, and Alumina Doped with Zirconia or Titania, J. Am. Ceram. Soc. 73 (1990) 1172-1175. doi:10.1111/j.11512916.1990.tb05175.x.

[42] A. Talimian, V. Pouchly, H.F. El-Maghraby, K. Maca, D. Galusek, Impact of high energy ball milling on densification behaviour of magnesium aluminate spinel evaluated by master sintering curve and constant rate of heating approach, Ceram. Int. 
45 (2019) 23467-23474. doi:10.1016/j.ceramint.2019.08.051.

[43] N. Benameur, G. Bernard-Granger, A. Addad, S. Raffy, C. Guizard, Sintering Analysis of a Fine-Grained Alumina-Magnesia Spinel Powder, J. Am. Ceram. Soc. 94 (2011) 1388-1396. doi:10.1111/j.1551-2916.2010.04271.x.

[44] F. Raether, P. Schulze Horn, Investigation of sintering mechanisms of alumina using kinetic field and master sintering diagrams, J. Eur. Ceram. Soc. 29 (2009) 2225-2234. doi:10.1016/j.jeurceramsoc.2009.01.025.

[45] P.P. Castañeda, The effective mechanical properties of nonlinear isotropic composites, J. Mech. Phys. Solids. 39 (1991) 45-71. doi:10.1016/0022-5096(91)90030-R.

[46] R.J. Green, A plasticity theory for porous solids, Int. J. Mech. Sci. 14 (1972) 215-224. doi:10.1016/0020-7403(72)90063-X.

[47] M. Abouaf, J.L. Chenot, A numerical model for hot deformation of metal powders, J. Theor. Appl. Mech. 5 (1986) 121-140.

[48] E. Arzt, M.F. Ashby, K.E. Easterling, Practical applications of hotisostatic Pressing diagrams: Four case studies, Metall. Trans. A. 14 (1983) 211-221. doi:10.1007/BF02651618.

[49] R. Chaim, M. Margulis, Densification maps for spark plasma sintering of nanocrystalline $\mathrm{MgO}$ ceramics, Mater. Sci. Eng. A. 407 (2005) 180-187. doi:10.1016/j.msea.2005.07.024.

[50] W. Ji, H. Xu, W. Wang, Z. Fu, Sintering dense nanocrystalline 3 YSZ ceramics without grain growth by plastic deformation as dominating mechanism, Ceram. Int. 45 (2019) 9363-9367. doi:10.1016/j.ceramint.2018.07.228.

[51] C. Manière, G. Kerbart, C. Harnois, S. Marinel, Modeling sintering anisotropy in ceramic stereolithography of silica, Acta Mater. 182 (2020). doi:10.1016/j.actamat.2019.10.032.

[52] J.D. Hansen, R.P. Rusin, M.-H. Teng, D.L. Johnson, Combined-Stage Sintering Model, J. Am. Ceram. Soc. 75 (1992) 1129-1135. doi:10.1111/j.1151-2916.1992.tb05549.x. 